\title{
Macaque Ventral Premotor Cortex Exerts Powerful Facilitation of Motor Cortex Outputs to Upper Limb Motoneurons
}

\author{
H. Shimazu, ${ }^{1}$ M. A. Maier, ${ }^{2}$ G. Cerri, ${ }^{1}$ P. A. Kirkwood, ${ }^{1}$ and R. N. Lemon ${ }^{1}$ \\ ${ }^{1}$ Sobell Department of Motor Neuroscience and Movement Disorders, Institute of Neurology, University College London, London WC1N 3BG, United \\ Kingdom, and ${ }^{2}$ University Paris-VI and Paris-VII and Institut National de la Santé et de la Recherche Médicale U483, 75005 Paris, France
}

The ventral premotor area (F5) is part of the cortical circuit controlling visuomotor grasp. F5 could influence hand motor function through at least two pathways: corticospinal projections and corticocortical projections to primary motor cortex (M1). We found that stimulation of macaque F5, which by itself evoked little or no detectable corticospinal output, could produce a robust modulation of motor outputs from M1. Arrays of fine microwires were implanted in F5 and M1. During terminal experiments under chloralose anesthesia, single stimuli delivered to $\mathrm{M} 1$ electrodes evoked direct $(\mathrm{D})$ and indirect $\left(\mathrm{I}_{1}, \mathrm{I}_{2}\right.$, and $\left.\mathrm{I}_{3}\right)$ corticospinal volleys. In contrast, single $\mathrm{F} 5$ shocks were ineffective; double shocks ( $3 \mathrm{msec}$ separation) evoked small I waves but no D wave. However, when the test (T) M1 shock was conditioned (C) by single or double F5 shocks, there was strong facilitation of $\mathrm{I}_{2}$ and $\mathrm{I}_{3}$ waves from M1, with $\mathrm{C}-\mathrm{T}$ intervals of $<1 \mathrm{msec}$. Intracellular recordings from 79 arm and hand motoneurons (MNs) revealed no postsynaptic effects from single F5 shocks. In contrast, these stimuli produced a robust facilitation of $\mathrm{I}_{2}$ and $\mathrm{I}_{3}$ EPSPs evoked from $\mathrm{M} 1$ ( $60 \%$ of MNs); this was particularly marked in hand muscle MNs (92\%). Muscimol injection in M1 reduced I waves from F5 and abolished the F5-induced facilitation of late I waves from M1, and of EPSPs associated with them. Thus, some motor effects evoked from F5 may be mediated by corticocortical inputs to M1 impinging on interneurons generating late corticospinal I waves. Similar mechanisms may allow F5 to modulate grasp-related outputs from M1.

Key words: motor cortex; movement (motion; motor activity); premotor; stimulation; corticospinal; monkey

\section{Introduction}

Area F5 in the ventral premotor cortex (PMv) is part of a corticocortical circuit involved in visuomotor control of the hand and in the elaboration of hand shapes appropriate for grasping visible objects. PMv is thought to be involved in transforming information about the location of an object in a visual frame of reference to one in a motor reference frame (Jeannerod et al., 1995; Kakei et al., 1999, 2001, 2003). F5 neurons show object-specific activity during grasp and muscimol injection into area F5 interferes with visually guided grasp (Murata et al., 1997; Rizzolatti et al., 1998, 2002; Fogassi et al., 2001).

If area F5 transforms visual information to motor outputs controlling hand shape, how does it influence the hand muscles that shape grasp? PMv, like other premotor areas, is characterized both by having separate corticospinal projections to the spinal cord and by reciprocal corticocortical connections with primary

Received 0ct. 20, 2003; revised Dec. 3, 2003; accepted Dec. 3, 2003.

This work was supported in part by the Wellcome Trust and by a European Union project (QLRT-1999-00448; Corticospinal Modeling). We thank Thomas Brochier, Rachel Spinks, Chris Seers, Helen Lewis, and Sam Shepherd for assistance.

Correspondence should be addressed to Professor Roger Lemon, Sobell Department of Motor Neuroscience and Movement Disorders, Institute of Neurology, University College London, Queen Square, London WC1N 3BG, UK. E-mail: rlemon@ion.ud.ac.uk.

H. Shimazu's present address: Department of Neurology, Tokushima University School of Medicine, Kuramotocho 2-50-1, Tokushima City 770-8503, Japan.

DOI:10.1523/JNEUROSCI.4731-03.2004

Copyright $\odot 2004$ Society for Neuroscience $\quad 0270-6474 / 04 / 241200-12 \$ 15.00 / 0$ motor cortex (M1) (Dum and Strick, 1991, 2002). PMv is electrically excitable, and rICMS in F5 evokes hand and digit movements (Hepp-Reymond et al., 1994; Godschalk et al., 1995; Dum and Strick, 2002). However, it is not known which pathways mediate these motor effects. Compared with other premotor areas, corticospinal outputs from F5 are few in number and do not project as far as the cervical enlargement, where motor nuclei supplying hand muscles are located, but terminate at midcervical levels (He et al., 1993; Galea and Darian-Smith, 1994).

F5 could also influence hand muscles via its dense corticocortical projections to M1 (Muakkassa and Strick, 1979; Godschalk et al., 1984; Matelli et al., 1986; Ghosh et al., 1987; Tokuno and Nambu, 2000; Dum and Strick, 2002). M1 is known to play a major role in hand control (Porter and Lemon 1993; Lemon et al., 2004). In a previous study, Cerri et al. (2003) showed that although stimulation of F5 through chronically implanted microwires was ineffective in producing EMG responses in contralateral hand muscles when delivered alone, these same stimuli could produce a robust facilitation of responses evoked from M1. EMG responses could be up to four times larger when conditioned by single shocks to F5, and up to 12 times larger for double F5 shocks. The earliest facilitation from F5 occurred at short intervals $(\sim 1 \mathrm{msec})$, indicating a local site of interaction of unknown location.

We have investigated the mechanisms underlying F5-M1 excitatory interactions in terminal experiments under general an- 
Table 1. Electrode locations

\begin{tabular}{|c|c|c|c|c|c|c|}
\hline Case & Species & Weight (kg) & Electrode type & Location of M1 electrodes & Location of F5 electrodes & $\begin{array}{l}\text { Effect of M1-rICMS } \\
\text { and threshold }\end{array}$ \\
\hline CS12 & M. fascicularis & 3.2 & Chronic & $\begin{array}{l}\text { - ve (3) } 5.5 \mathrm{~mm} \text {, ant bank CS, wm } \\
\text { + ve (2) } 2.0 \mathrm{~mm} \text {, ant bank CS, V }\end{array}$ & $\begin{array}{l}\text { - ve (1) } 3.0 \mathrm{~mm} \text {, inf bank AS, V } \\
\text { + ve (2) } 2.0 \mathrm{~mm} \text {, inf bank AS, V }\end{array}$ & $\begin{array}{l}\text { II-V extension } \\
55 \mu \mathrm{A}\end{array}$ \\
\hline CS13 & M. fascicularis & 3.1 & Chronic & $\begin{array}{l}\text { - ve (2) } 4.5 \mathrm{~mm} \text {, ant bank CS, VI } \\
\text { + ve (1) } 2.0 \mathrm{~mm} \text {, ant bank CS, V }\end{array}$ & $\begin{array}{l}\text { - ve (6) } 2.8 \mathrm{~mm} \text {, inf bank AS, V } \\
\text { + ve (5) } 6.0 \mathrm{~mm} \text {, inf bank AS, VI }\end{array}$ & $\begin{array}{l}\text { Thumb flexion } \\
35 \mu \mathrm{A}\end{array}$ \\
\hline CS14 & M. fascicularis & 4.4 & Chronic & $\begin{array}{l}\text { - ve (4) } 4.0 \mathrm{~mm} \text {, ant bank CS, V } \\
\text { + ve (3) } 2.2 \mathrm{~mm} \text {, ant bank CS, V }\end{array}$ & $\begin{array}{l}\text { - ve (10) } 2.2 \mathrm{~mm}, \text { inf bank AS, V/VI } \\
\text { + ve (7) } 4.5 \mathrm{~mm} \text {, inf bank AS, II/III }\end{array}$ & $\begin{array}{l}\text { Thumb abduction } \\
50 \mu \mathrm{A}\end{array}$ \\
\hline CS16 & M. mulatta & 6.9 & Acute & $\begin{array}{l}\text { - ve (2) } 2.8 \mathrm{~mm} \text {, convx PG, V/VI } \\
\text { + ve (1) } 2.8 \mathrm{~mm} \text {, ant bank CS, V }\end{array}$ & $\begin{array}{l}\text { - ve (4) } 1.2 \mathrm{~mm}, \text { inf bank AS, III } \\
\text { + ve (3) } 1.5 \mathrm{~mm} \text {, inf bank AS, II/III }\end{array}$ & Not tested \\
\hline CS17 & M. mulatta & 5.9 & Acute & $\begin{array}{l}\text { - ve (2) } 1.5 \mathrm{~mm} \text {, ant bank CS, V } \\
\text { + ve (1) } 2.0 \mathrm{~mm} \text {, ant bank CS, V }\end{array}$ & $\begin{array}{l}\text { - ve (4) } 1.2 \mathrm{~mm} \text {, inf bank AS, III } \\
\text { + ve (3) } 1.2 \mathrm{~mm} \text {, inf bank AS, II }\end{array}$ & Not tested \\
\hline
\end{tabular}

Data are presented as polarity of electrode (-ve/+ve), electrode number (number in parentheses), depth of tip from surface, location, and lamina. CS, Central sulcus; $\mathrm{AS}$, arcuate sulcus; convx, convexity of precentral gyrus (PG); ant, anterior; inf, inferior; wm, white matter.

esthesia. We show that conditioning F5 stimulation produces a strong facilitation of the late corticospinal volleys evoked from $\mathrm{M} 1$, referred to as $\mathrm{I}_{2}$ and $\mathrm{I}_{3}$ waves. Postsynaptic responses to these later waves in hand motoneurons were also enhanced. The detailed time course of the facilitation from F5 suggested that peak effects were observed at the times at which I waves were generated in M1. Finally, we demonstrated that the facilitation from F5 of corticospinal activity and the associated motoneuronal responses were abolished by local microinjection of the $\mathrm{GABA}_{\mathrm{A}}$ agonist muscimol into the hand area of M1.

These facilitatory interactions between F5 and M1 may also be involved in visuomotor transformations during grasp.

\section{Materials and Methods}

The study was performed on five adult, purpose-bred monkeys (Macaca fascicularis and Macaca mulatta; cases CS12, CS13, CS14, CS16, and CS17) (Table 1). Results of related experiments in two of these cases (CS13 and CS14) were reported by Cerri et al. (2003). All procedures were in accordance with the United Kingdom Animals (Scientific Procedures) Act 1986.

The overall design of the approach is indicated in Figure 1. Under general anesthesia, single bipolar stimuli were delivered to the hand area of M1, using an array of intracortical microwire electrodes (Fig. 1, open circles). The corticospinal volleys generated by these stimuli were recorded from the corticospinal tract using surface electrodes on the contralateral DLF at both a rostral site [rostral volley (Rv), C3 segment] and a caudal site [caudal volley $(\mathrm{Cv}), \mathrm{C} 7$ or C8]. Postsynaptic potentials evoked in motoneurons by these volleys were recorded intracellularly using glass micropipettes. Motoneurons were identified antidromically from electrodes mounted on upper limb nerve trunks. The M1 stimuli were conditioned with either single or paired shocks to area F5 using another microwire array. The effects of interactions between the condition (F5) and test (M1) shocks were analyzed both in terms of the corticospinal volleys and motoneuron postsynaptic potentials.

Identification and chronic implantation of hand representations in F5 and M1. In three of the monkeys (CS12, CS13, and CS14) (Table 1), the hand/digit motor representations in F5 and M1 were identified physiologically, as described fully in our previous study (Cerri et al., 2003). A chamber was first implanted over the precentral gyrus under deep general anesthesia and aseptic precautions, with a full program of postoperative analgesic and antibiotic treatment. Chamber location was guided by an initial structural MRI scan. Subsequently, the motor representations in F5 and M1 were defined using repetitive intracortical microstimulation (rICMS) under light sedation with ketamine and medetomidine $\mathrm{HCl}$ (Dormitor; Ramsgate, Kent, UK). The doses were $3.6 \mathrm{mg} / \mathrm{kg}^{-1} \mathrm{ket}$ amine and $0.044 \mathrm{mg} / \mathrm{kg}^{-1}$ Dormitor, both given intramuscularly.

When rICMS mapping was complete, small arrays of fine lowimpedance $(\sim 20 \mathrm{k} \Omega)$ elgiloy microwire electrodes were implanted chronically at the center of the hand and digit representations under full anesthesia; four to five electrodes were implanted in M1 and in F5. Tips of microwires were targeted at the inferior bank of the arcuate sulcus (F5) and rostral bank of the central sulcus (M1) and were between 3 and $6 \mathrm{~mm}$ from the pial surface. The electrodes were mounted in a single flat array, with an interelectrode distance of 1-1.3 mm. Electrodes were connected to a small miniature D-connector mounted on the skull.

Terminal experiment. Terminal experiments were performed as described by Maier et al. (1998, 2002). In brief, all preparatory surgery was performed under deep isoflurane anesthesia. Cuff electrodes were mounted on the median, ulnar, and radial nerves at the axilla $\mathrm{Ma}, \mathrm{Ua}$, and $\mathrm{Ra}$, respectively); median and ulnar nerves at the wrist (Mw and $\mathrm{Uw}$ ); and the deep radial nerve (DR). A laminectomy over spinal segments C3 to Th1 and an occipital craniotomy were performed. When surgery was complete, isoflurane was discontinued and $\alpha$-chloralose was given $\left(50-80 \mathrm{mg} / \mathrm{kg}^{-1}\right.$, i.v.). The animal was mounted in a spinal frame and headholder, with clamps on the vertebral column at Th3 and in the lumbar region, and then paralyzed with pancuronium bromide (Pavulon; OR-Technika, Cambridge, UK) at a dose of $0.3 \mathrm{mg} \cdot \mathrm{kg}^{-1} \cdot \mathrm{hr}^{-1}$ intravenously and artificially ventilated at a rate of $45 \mathrm{cycles} / \mathrm{min}^{-1}$. Adequacy of the anesthesia was assessed continuously by reference to the blood pressure, heart rate, and pupillary reflexes. Small doses (2-4 mg/ $\mathrm{kg}^{-1}$, i.v.) of pentobarbitone (Sagatal; Rhone Merieux, Harlow, UK) were administered when necessary. Body temperature was carefully maintained between 37 and $39^{\circ} \mathrm{C}$. Fluid balance and blood gases were monitored and maintained; each animal remained in good physiological condition throughout the recording. Mean blood pressure was maintained above $80 \mathrm{mmHg}$.

Location of cortical-stimulating electrodes in terminal experiments. The surface location of intracortical microwire electrodes in the five different cases is shown in Figure 2: the cathode (negative) (Fig. 2A-E, -) and anode (positive) (Fig. $2 A-E,+$ ) that were used in the terminal experiment have been marked in each case. M1 electrodes were located in the anterior bank of the central sulcus, and F5 electrodes were located in the bank of the inferior limb of the arcuate sulcus several millimeters lateral to the spur region. In the final two monkeys in this series (CS16 and CS17), the pairs of intracortical-stimulating electrodes were implanted acutely in the terminal experiment. Electrode placement was guided by magnetic resonance imaging (MRI) and by the results from the three monkeys with chronic implants.

Intracortical stimulation of areas F5 and M1. In both chronically and acutely implanted monkeys, cortical areas F5 and M1 were stimulated using monophasic current pulses applied to pairs of intracortical electrodes. The duty cycle was $3 \mathrm{~Hz}$. The intensities ranged from 50 to 400 $\mu \mathrm{A}$, although in the majority of cases they were $\leq 200 \mu \mathrm{A}$. These currents were used to activate a significant proportion of the cortical output to hand and arm motoneurons (Maier et al., 2002). The physical spread of such currents is probably $<1 \mathrm{~mm}$ (Ranck, 1975; Lemon, 1984; Tokuno and Nambu, 2000). At the start of each experiment, every combination of electrode was tested and the size and number of descending volleys evoked were compared. The final combination and polarity of electrodes used for bipolar stimulation were selected for optimal descending activity with low threshold. In the case of chronic implants (CS12, CS13, and CS14), the same electrode combinations found to be effective for facilitation of hand muscle EMG (Cerri et al., 2003) were used. 


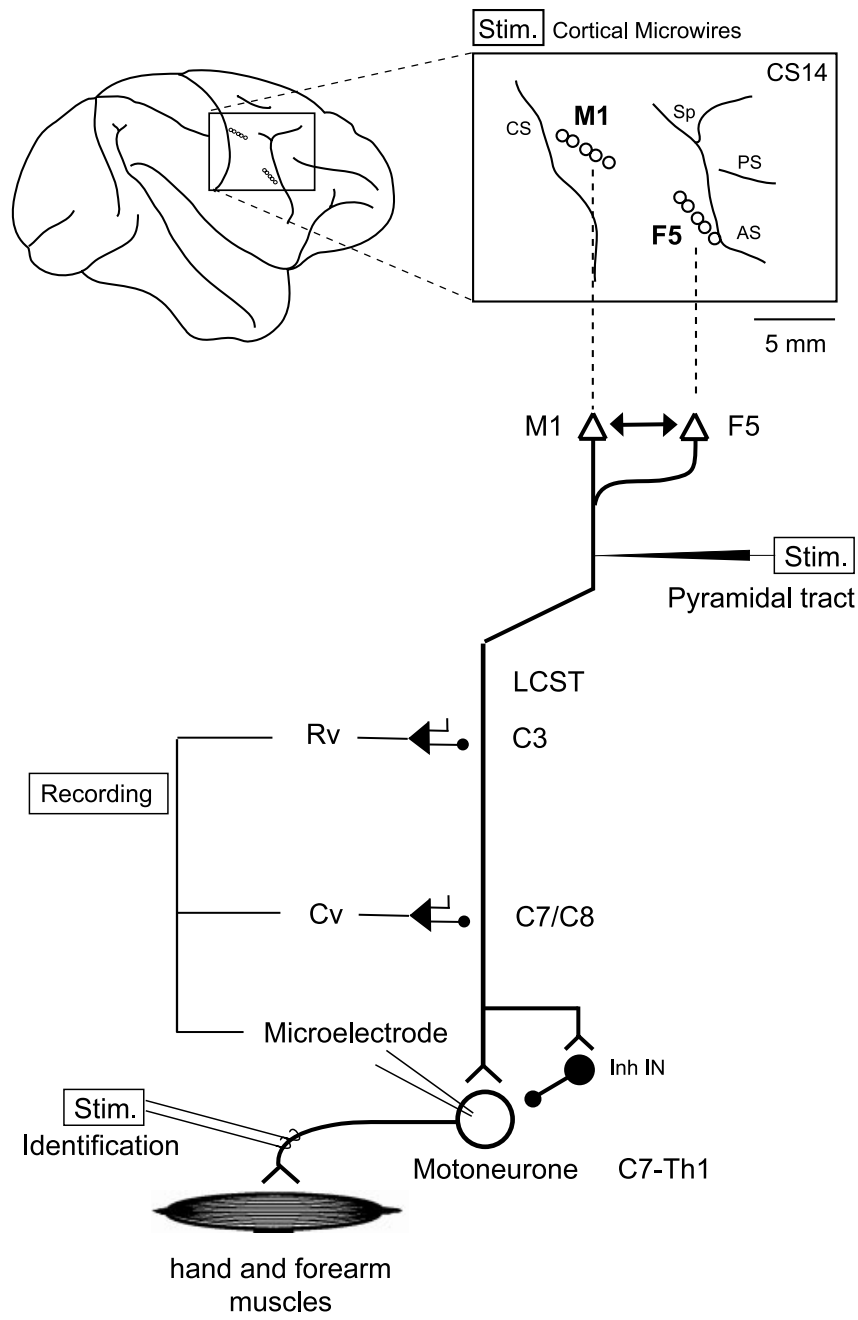

Figure 1. Schematic diagram of the experiment. The inset in the top part of the figure indicates sites within the primary motor cortex (M1) and PMv (F5) that were each chronically implanted with five microwires in one of the five monkeys investigated (CS14; see Materials and Methods). Each open circle indicates a microwire electrode. The M1 electrodes were located in the anterior bank of the central sulcus (CS), and the F5 electrodes were located in the inferior bank of the arcuate sulcus (AS). Sp, Spur; PS, principal sulcus. The bottom part of the figure indicates that descending volleys evoked from M1 and F5 were recorded from the lateral corticospinal tract (LCST) at two spinal levels: a rostral level (Rv) at C 3 and a caudal level (Cv), usually at C7 or C8. EPSPs and IPSPs [the latter mediated by segmental inhibitory interneurons (Inh IN)] were recorded intracellularly from arm and hand muscle motoneurons in the cervical enlargement, and these were antidromically identified from peripheral nerves. Volleys and postsynaptic potentials evoked from M1 and F5 were compared with those from stimulation of the medullary PT.

Condition (C), test ( $\mathrm{T}$ ), and combined (C-T) stimuli were interleaved and delivered as follows. "Conditioning stimuli" were single or double shocks to F5 (duration, $0.2 \mathrm{msec}$; up to $400 \mu \mathrm{A}$ ). "Test stimuli" were single shocks to M1 (duration, $0.2 \mathrm{msec}$; up to $400 \mu \mathrm{A}$ ). "Combined condition-test stimuli" were delivered either together (simultaneous delivery; $\mathrm{C}-\mathrm{T}=0$ ), positive ( $\mathrm{F} 5$ up to $30 \mathrm{msec}$ before $\mathrm{M} 1$ ) or negative (M1 up to 3.6 msec before F5).

Stimulation of the pyramidal tract. An electrode (varnish-insulated tungsten; tip impedance, $20-30 \mathrm{k} \Omega$ at $1 \mathrm{kHz}$ ) was inserted just rostral to obex and $0.5-1.5 \mathrm{~mm}$ lateral to the midline, ipsilateral to the stimulated hemisphere. Conventional electrophysiological criteria were used for final pyramidal tract (PT) electrode positioning (Maier et al., 1998). Stimuli were 10-200 $\mu \mathrm{A}(0.1 \mathrm{msec})$. In CS14, stimuli were delivered through implanted PT electrodes (Cerri et al., 2003).

Recording and analysis of corticospinal volleys. Corticospinal volleys excited from the PT, from M1 and from F5, were recorded from the surface of the contralateral dorsolateral funiculus (DLF) at a rostral site (usually C3) and at a caudal site close to the region from which motoneuron recordings were made ( $\mathrm{C} 7$ or $\mathrm{C} 8)$ and were each referenced to an electrode located on nearby muscle tissue. Corticospinal volleys and stimulus trigger signals were acquired using a CED 1401plus interface (CED, Cambridge, UK), with a sampling rate of $25 \mathrm{kHz}$. Volleys were averaged in relation to stimulus triggers $(\mathrm{C}, \mathrm{T}$, or $\mathrm{C}-\mathrm{T})$, with 100 shocks per condition, and the peak-to-peak amplitude and latency of each component $\left(D, I_{1}, I_{2}, I_{3}\right)$ was measured from these averages. The effect of conditioning stimulation on each component was analyzed on a sweepby-sweep basis (see Results) (see Fig. 10).

Intracellular recordings from motoneurons were made with glass microelectrodes filled with $3 \mathrm{~m}$ potassium acetate and having a DC resistance of 2-5 M $\Omega$. A small pressure foot was used to reduce movement of the spinal cord. All motoneurons were identified antidromically from the forelimb nerves. Intracellular and cord surface recordings were digitized directly at $10 \mathrm{kHz}$ using a 1401 plus interface (CED). Membrane potential was monitored throughout the recording, and only data from stable periods of recording were used for analysis (membrane potential, $<-50$ $\mathrm{mV}$ ). Latency and amplitude measurements were made from a number of single traces.

Intracortical injection of muscimol. In cases CS12, CS13, and CS14, a $0.5 \%$ solution of the $\mathrm{GABA}_{\mathrm{A}}$ agonist muscimol (catalog number M-1523; Sigma, St. Louis, MO) was injected into $\mathrm{M} 1$ as close as possible $(<2.0$ $\mathrm{mm}$ ) to the M1 microwire array. A small hole was made in the dura with a 27 gauge needle, and a 29 gauge Hamilton syringe needle advanced to a depth of $4 \mathrm{~mm}$ below the pia. Over a 3-5 min period, $0.2-1.0 \mu \mathrm{l}$ of the muscimol solution was injected. After a delay of $2-4 \mathrm{~min}$, the needle was raised by $1 \mathrm{~mm}$ and an additional injection was made, and this was repeated at depths of $2 \mathrm{~mm}$ and then $1 \mathrm{~mm}$ below the pia. One (CS13) or two (CS12 and CS14) tracks were made within $2 \mathrm{~mm}$ of the M1 array, and the total volume of muscimol injected was 6,3 , and $1.6 \mu \mathrm{l}$ in CS12, CS13, and CS14, respectively.

Histology. At the end of the experiment, small electrolytic lesions were placed at the cortical stimulation sites by passing DC $(20 \mu \mathrm{A}$ for $20 \mathrm{sec}$; tip positive). The animal was given an overdose of barbiturate and perfused through the heart with formal saline. Entry points of microwire arrays and the Hamilton microinjection needle were confirmed by photography of the fixed cortical tissue. All sites of stimulating electrodes were confirmed histologically (Suzuki and Azuma, 1976). Frozen sections $(50 \mu \mathrm{m})$ were cut, mounted, and Nissl stained. Each section was inspected carefully for electrode tracks, and sample sections were digitized.

\section{Results}

\section{Location of stimulating sites in M1 and F5}

\section{M1 electrodes}

In every case, the $\mathrm{M} 1$ electrodes were located in the anterior bank of the central sulcus: in four of five cases, the tip of the effective M1 cathode was in the deep layers (lamina V/VI) (Table 1). M1 anodes all lay in lamina $\mathrm{V}$. In the three chronic cases, these electrodes were located in the M1 hand area, as confirmed by previous rICMS mapping. rICMS through the implanted microwires yielded digit movements with currents between 35 and $55 \mu \mathrm{A}$ in all cases (Table 1) [histology indicating the location of electrode tips in case CS14 is presented in Fig. 1 D of Cerri et al. (2003)], and single shocks delivered to M1 electrode pairs evoked monosynaptic EPSPs in hand and finger muscle motoneurons (see below).

\section{F5 electrodes}

F5 electrodes were located in the bank region of the inferior limb of the arcuate sulcus several millimeters lateral to the spur region. The tips of effective cathodes (Table 1) were either in deep layers (CS12, CS13, CS14) or in lamina III (CS16, CS17), whereas anodes were located in deep layers (V/VI in CS12 and CS13) or superficial layers (II/III). 

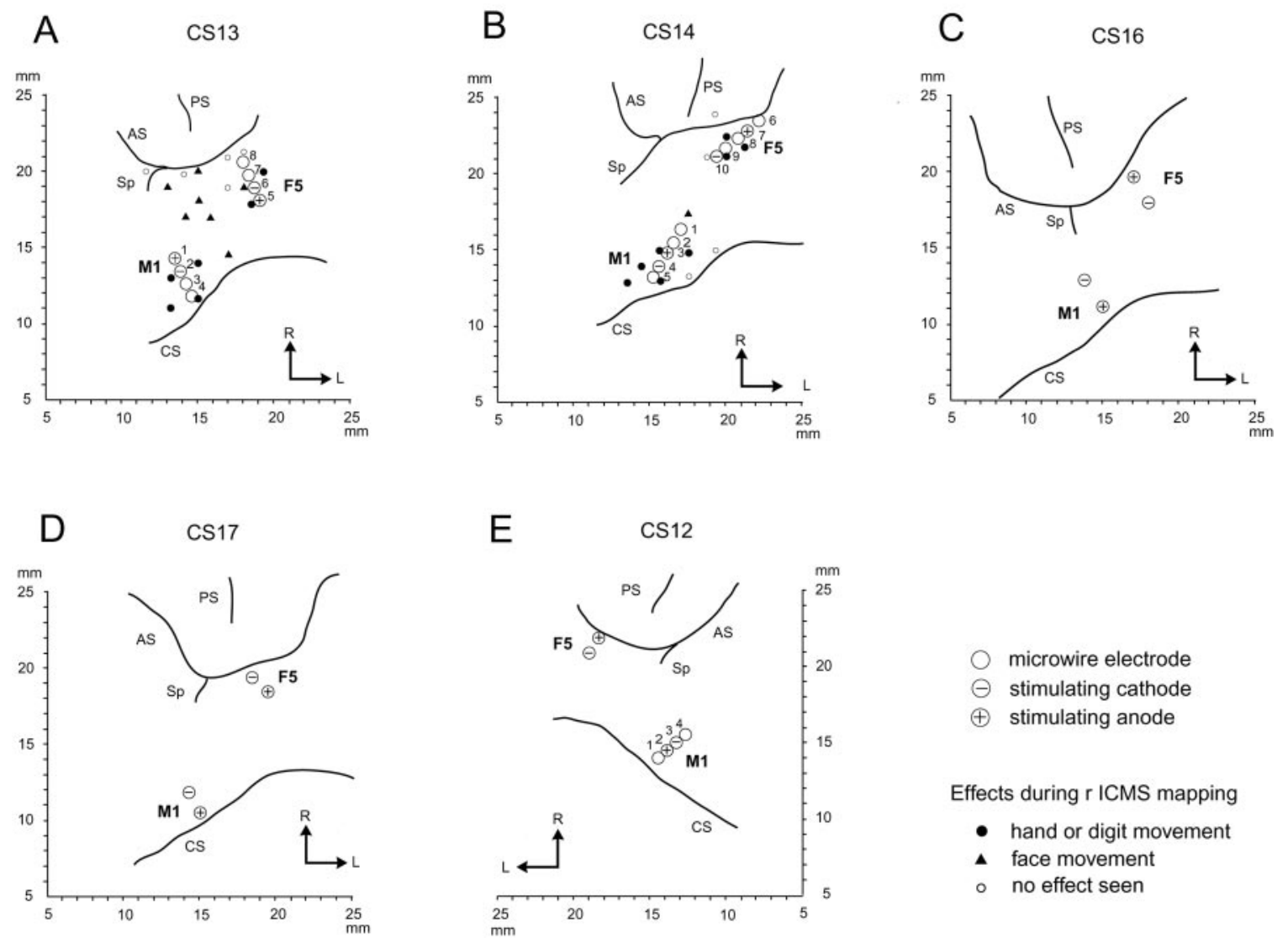

$\odot$ microwire electrode
$\ominus$ stimulating cathode
$\oplus$ stimulating anode

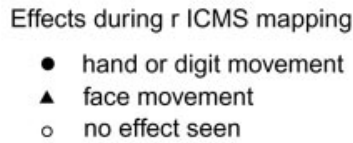

Effects during r ICMS mapping

- face movement

- no effect seen

Figure 2. Location of implanted microwire electrodes. Surface cortical maps of five macaque monkeys (CS13, CS14, CS16, CS17, and CS12) showing the location of stimulating electrodes in the primary motor cortex (M1) and PMv (F5). Stereotaxic coordinates in the rostral (R)- caudal and mediolateral (L) directions are indicated on the ordinate and abscissa, respectively. In all cases, the cathodal electrode is shown as $\ominus$ and anodal as $\oplus$. In $\mathrm{CS} 13, \mathrm{CS} 14$, and $\mathrm{CS} 12$, circled numbers indicate points of penetration of chronically implanted microwires in M1 and F5, which were centered on the respective hand/digit representations in these areas. In CS13 and CS14, these were defined by prior mapping with rICMS. Mapping penetrations that yielded low-threshold (M1, 8-10 $\mu$ A; F5, 22-28 $\mu \mathrm{A})$ movements of digits $(-)$ or face $(\mathbf{\Delta})$ are shown. No effects were obtained in penetrations marked with a small open circle. In monkey $\operatorname{CS} 13(A)$, the microwire implant in M1 carried four electrodes (1-4), varying in length from 3 to $5 \mathrm{~mm}$. In monkey $\mathrm{CS} 14(B)$, both the $\mathrm{M} 1$ and $\mathrm{F} 5$ implants had five electrodes each (M1, 1-5; F5, $6-10)$, and all electrodes were located in the anterior bank of the $C S$ and inferior bank of the AS, respectively. In CS16 and CS17, pairs of electrodes were introduced into $F 5$ and $M 1$ in the terminal experiment, with locations guided by the results from CS13 and 14 and by recording of corticospinal volleys. The location of the tips of the most effective electrode pairs in each case are listed in Table 1.

\section{Corticospinal volleys evoked from M1 and F5}

M1 stimulation

A single stimulus applied to M1 evoked a series of D and I waves in the corticospinal tract (Patton and Amassian, 1954; Kernell and $\mathrm{Wu}, 1967$; Maier et al., 2002). Figure $3 A$ gives examples of averaged volleys recorded at the $\mathrm{C} 8$ spinal level; the threshold for these volleys was $25 \mu \mathrm{A}$. At $100 \mu \mathrm{A}$, a small early $(1.4 \mathrm{msec}) \mathrm{D}$ wave and a later and larger $\mathrm{I}_{1}$ wave were seen. As the stimulus intensity was raised, later I waves occurring at regular intervals of 1-1.5 msec were recruited: these were the $\mathrm{I}_{2}, \mathrm{I}_{3}, \mathrm{I}_{4}$, and $\mathrm{I}_{5}$ waves. The conduction velocity $(\mathrm{CV})$ of the different waves was deduced from simultaneous recordings at $\mathrm{C} 3$ and $\mathrm{C} 7$. As expected from previous studies (Kernell and Wu, 1967; Maier et al., 2002), the D and succeeding I waves had a very similar CV: in CS17, for example, the $\mathrm{D}, \mathrm{I}_{1}, \mathrm{I}_{2}$, and $\mathrm{I}_{3}$ waves all had a CV of $\sim 83 \mathrm{~m} \cdot \mathrm{sec}^{-1}$.

\section{F5 stimulation}

There were three differences in responses from F5 compared with those from M1 (Fig. 3B). First, no D waves were seen in any of the five cases; second, I wave responses were generally smaller and later than those from M1; and finally, single shocks evoked relatively little activity. With double shocks (interstimulus interval, 3 $\mathrm{msec}$ ), some activity was seen, with $\mathrm{I}_{3}$ being the clearest component. In three cases in which volley CV was determined (CS14, CS16, and CS17), there was no significant difference between the
$\mathrm{CV}$ of volleys from M1 (mean of 12 separate estimates, $81 \pm 7$ $\mathrm{m} \cdot \mathrm{sec}^{-1}$ ) and that of F5 volleys (mean of 8 estimates, $81 \pm 7$ $\left.\mathrm{m} \cdot \mathrm{sec}^{-1}\right)(t$ test; $p=0.97)$.

\section{Effects of F5-M1 interactions on corticospinal volleys}

These interactions were tested by interleaving C (F5), T (M1), and $\mathrm{C}-\mathrm{T}(\mathrm{F} 5+\mathrm{M} 1)$ stimuli (see Materials and Methods). The intensity of the test M1 shock was clearly submaximal for evoking a volley, whereas that of the conditioning F5 shock was generally just above or just below threshold for evoking any detectable descending volleys.

The basic finding is presented in Figure 4: when F5 stimulation preceded the M1 test shock by $\sim 3 \mathrm{msec}$, there was a clear facilitation of the later components of the corticospinal response. The examples given in Figure 4 are from CS14 (Fig. $4 A-D$ ) and CS17 (Fig. $4 E-H$ ). In both cases, M1 stimulation, given alone, evoked a small $\mathrm{D}$ wave and larger $\mathrm{I}_{1}, \mathrm{I}_{2}$, and $\mathrm{I}_{3}$ waves (Fig. $4 B, F$ ). Conditioning F5 stimulation [just suprathreshold for detectable descending activity in CS14 (Fig. $4 A$ ) or just subthreshold in CS17 (Fig. 4E)] produced a marked increase in the amplitude of both the $\mathrm{I}_{2}$ and $\mathrm{I}_{3}$ waves but not of the earlier $\mathrm{D}$ or $\mathrm{I}_{1}$ waves (Fig. $4 C, G)$. This is best seen in Figure 4, $D$ and $H$, where any effects attributable to the F5 shock alone have been subtracted from the conditioned response [i.e., (F5 + M1) - F5]. Any differences in 

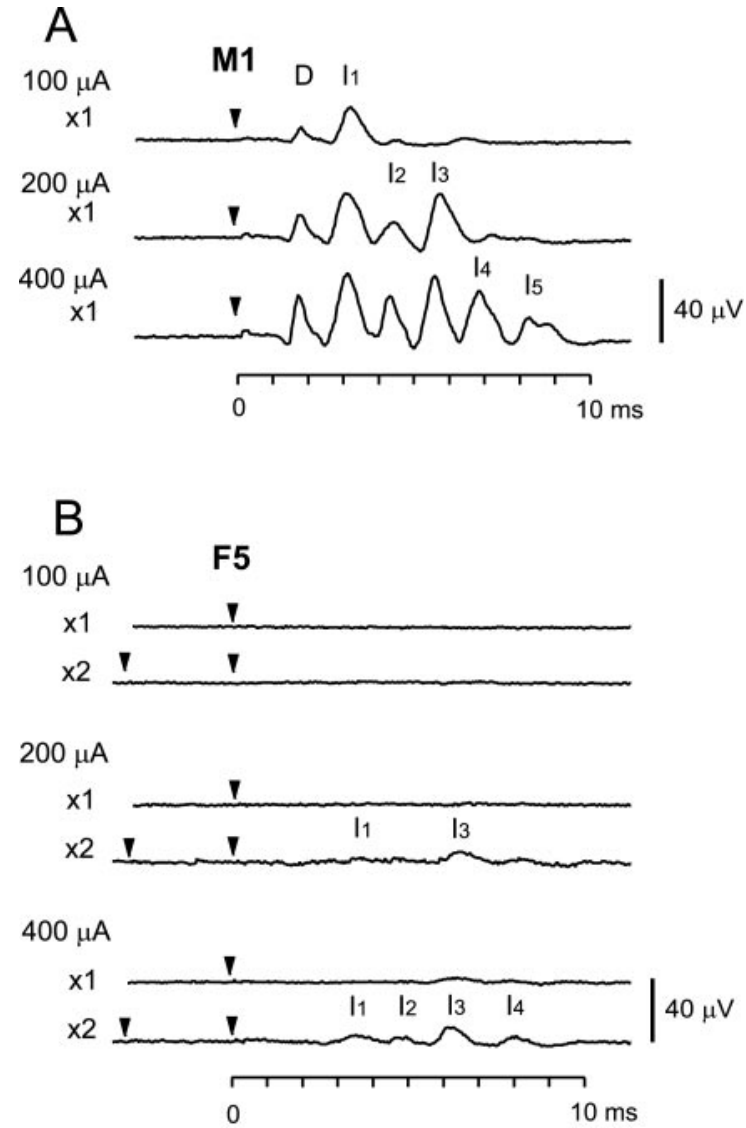

Figure 3. Corticospinal volleys evoked from $\mathrm{M} 1$ and $\mathrm{F} 5$. Surface recordings from $\mathrm{C} 8$ (monkey (S16) are shown. Stimulus intensities are as indicated (duration, $0.2 \mathrm{msec}$ ). Shown are the averages of 100 sweeps. A, Single shocks to M1 (arrowhead)-evoked responses consisting of a direct wave (D) and a succession of indirect $(I)$ waves $\left(I_{2}, I_{3}\right.$, etc.). The threshold for volleys was $25 \mu$ A. B, No clear responses were obtained to single shocks to F5, except at $400 \mu$ A. Double shocks (interstimulus interval, 3 msec) evoked a clear $\mathrm{I}_{3}$ wave; no D wave was observed. In this and all subsequent figures, volley recordings are shown with positivity down.

this response (solid line) from the response to $\mathrm{M} 1$ alone (dashed line) represents the conditioning effect of the F5 stimulus: the facilitation of the $\mathrm{I}_{2}$ and $\mathrm{I}_{3}$ is clear in both cases, with no effect on either the D or $\mathrm{I}_{1}$ waves. Facilitatory effects were usually obtained from only one or two pairs of F5 electrodes; in CS13 and CS14, the effective electrodes were the same ones found to produce facilitation of EMG in our previous study (Cerri et al., 2003).

Figure 5 shows the results obtained for a series of different C-T intervals in CS14 (Fig. 5A-D) and CS17 (Fig. 5E-H): note that while facilitation of the $\mathrm{I}_{3}$ was present at $\mathrm{C}-\mathrm{T}$ intervals of 0 and $1.6 \mathrm{msec}$, the augmentation of the $\mathrm{I}_{2}$ was not seen until longer intervals (3.2 and $4 \mathrm{msec}$ ) (Fig. $5 \mathrm{C}, D, G, H$ ). Clear and significant increases in $\mathrm{I}_{2}$ or $\mathrm{I}_{3}$ waves as a result of $\mathrm{F} 5$ conditioning are marked by asterisks $\left({ }^{*} p<0.05\right.$; ${ }^{* *} p<0.01$; paired $t$ test on volley amplitudes). Clear effects on $\mathrm{D}$ and $\mathrm{I}_{1}$ waves were not seen at any of the intervals tested. There was no sign of suppression of any component by F5 stimulation.

Broadly similar results were obtained with double F5 shocks (interval, $3 \mathrm{msec}$ ) (Fig. 6A,B). The findings were replicated in the other three cases. A more detailed description of the time course of F5-M1 interactions is presented below (see Fig. 10).

\section{Postsynaptic responses in hand and forearm motoneurons} Intracellular recordings were made from a total of 79 antidromically identified motoneurons (CS12:23, CS13:19, CS14:15, CS16:
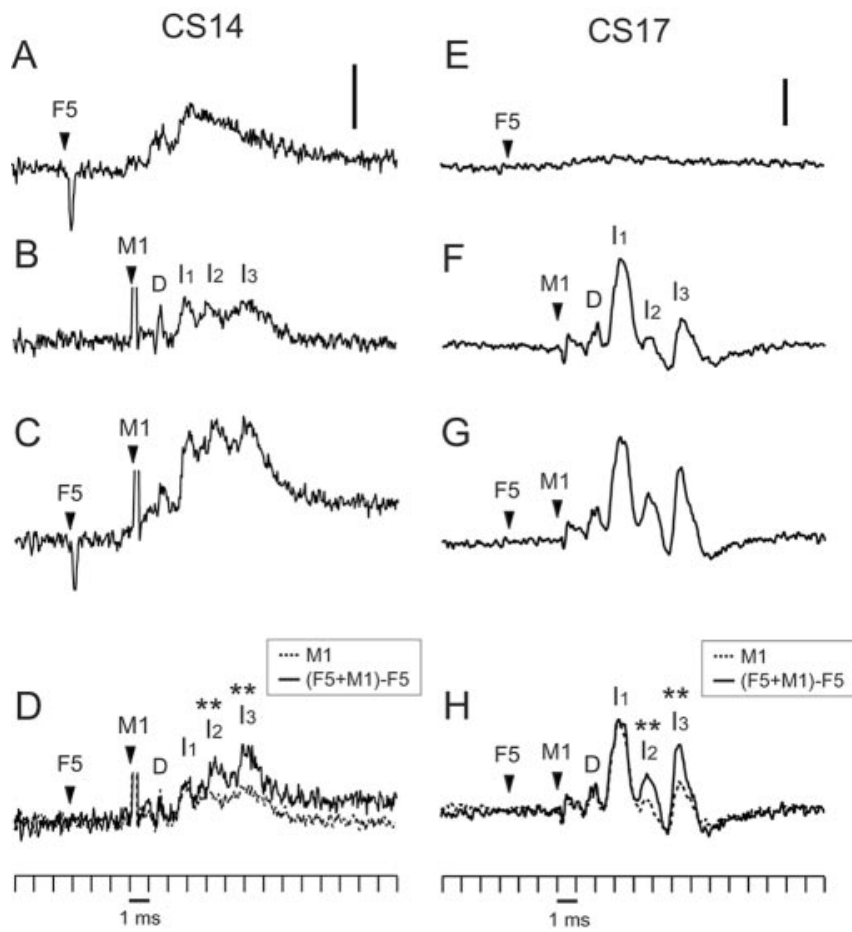

Figure 4. Facilitation of late I waves evoked from M1 by conditioning stimulus to F5. Surface recordings from $C 3$ segment in two monkeys $C S 14(A-D)$ and $C S 17(E-H)$. The averages of 100 sweeps are shown. $A, E$, Response to conditioning $\mathrm{F} 5$ shock alone; subthreshold for any response in $E$. $B, F$, Response to test $M 1$ alone. $C, G$, Condition and test (F5 $+\mathrm{M} 1)$ produced a clear facilitation of the later I waves $\left(I_{2}\right.$ and $\left.I_{3}\right)$. In $D$ and $H$, the amount of facilitation is shown by plotting the test (M1) response alone (...) with superimposed the conditioned response (__ ), after any effects from the conditioning (F5) shock alone had been subtracted. Stimulation: A-D: F5, $1 \times 200 \mu \mathrm{A} ; \mathrm{M1}, 1 \times 180 \mu \mathrm{A} ; \mathrm{E}-\mathrm{H}$ : F5, $1 \times 200 \mu \mathrm{A} ; \mathrm{M1}, 1 \times 150 \mu \mathrm{A}$. Calibration, $10 \mu \mathrm{V}$.

15, and CS17:7) recorded in spinal segments C7, C8, and Th1. Some of these motoneurons innervated wrist or finger flexors: 21 and 19 were identified from the ulnar and median nerves at the axilla ( $\mathrm{Ua}$ and $\mathrm{Ma}$ ), respectively. Others innervated wrist or finger extensors (22, deep radial (DR) nerve). An additional four motoneurons were innervated from radial nerve at the axilla (Ra). Finally, 13 were identified as supplying intrinsic hand muscles [ulnar (Uw; 11) or median nerve (Mw; 2) at the wrist].

\section{Response to PT stimulation}

Response to PT stimulation was tested in 75 motoneurons: most (95\%) gave a monosynaptic EPSP, which in many cases (45\%) was followed by a disynaptic IPSP; $20 \%$ of motoneurons responded with an oligosynaptic EPSP (Maier et al., 1998).

\section{Responses to M1 and F5 stimulation}

M1 and F5 stimulation responses were tested in all 79 motoneurons, using a single shock of $200 \mu \mathrm{A}$ (M1) in all experiments. For F5, a single $200 \mu \mathrm{A}$ shock was used in CS14 and CS17, and double $200 \mu \mathrm{A}$ shocks (3 msec intershock interval) in the other cases. The short duration of stable intracellular recording prevented the investigation of a detailed F5-M1 interaction time course, and one $\mathrm{C}-\mathrm{T}$ interval was tested (3.0 msec between F5 and M1).

A variety of postsynaptic potentials were observed (Figs. 6, 7). The categorization of EPSPs was made according to their association with a particular component of the descending volley, recorded from the surface of the same spinal segment in which the motoneuron was sampled. Maier et al. (2002) argued that the tight coupling between each volley component and the succeed- 


\section{CS14}

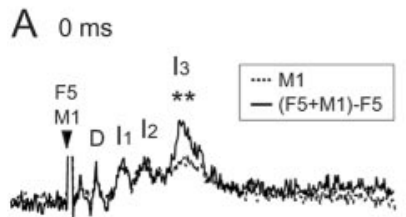

B $2.0 \mathrm{~ms}$

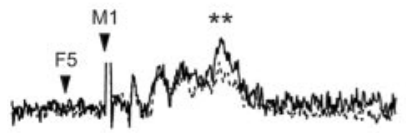

C $3.2 \mathrm{~ms}$

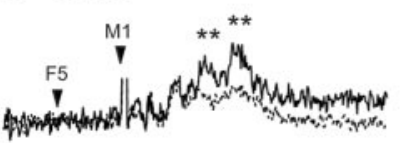

D $4.0 \mathrm{~ms}$

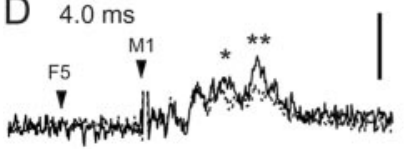

11111111111111111
CS17

E $0 \mathrm{~ms}$

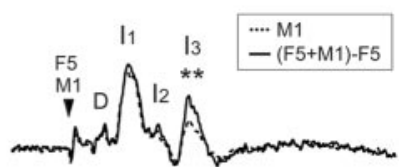

F $2.0 \mathrm{~ms}$

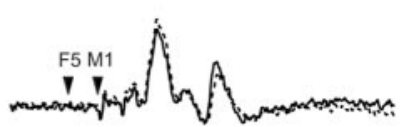

G $3.2 \mathrm{~ms}$
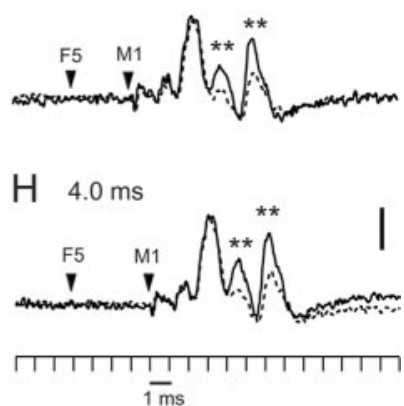

Figure 5. Time course of facilitation from F5. Surface recordings from the same cases as Figure 4, with identical stimulus intensities. Data are plotted as in Figure 4, D and H: test (M1) alone, - - - ; conditioned response (F5 + M1) minus condition (F5) alone (F5), __. . Data in $A-D$ and $E-H$ are plotted for different $C-T$ intervals $(0,2,3.2$, and $4 \mathrm{msec})$. Note that at short C-T intervals $\left(A, B, E, F, 0\right.$ and 2 msec), facilitation of $\mathrm{I}_{3}$ was observed, whereas both $\mathrm{I}_{2}$ and $\mathrm{I}_{3}$ were facilitated at longer intervals $(C, D, G, H) .{ }^{*} p<0.05 ;{ }^{* *} p<0.01 ; t$ test comparison of ( $F 5$ + M1) $-F 5$ with M1 alone.

ing EPSP, plus the short segmental delays, was consistent with these EPSPs representing monosynaptic action of impulses grouped within that particular component. Thus, D-EPSPs occurred with a segmental delay after arrival of the $\mathrm{D}$ wave that was in the monosynaptic range $(0.6-1.3 \mathrm{msec})$ (Maier et al., 2002). Similar criteria were adopted for $\mathrm{I}_{1}$-EPSPs; all other EPSPs, occurring in relation to the $\mathrm{I}_{2}$ and $\mathrm{I}_{3}$ waves, were classified as "late" EPSPs. Similarly, IPSPs were classified according to a disynaptic delay after the D wave (1.4-2.0 msec) (Maier et al., 2002) as D-IPSPs, $\mathrm{I}_{1}$-IPSPs, or late IPSPs.

Figure $6 A$ shows typical intracellular recordings from an ulnar hand motoneuron $(\mathrm{MN}$; bottom traces), together with the cord surface recording from the same (C8) segment (top traces). M1 stimulation alone produced a typical sequence of $\mathrm{D}, \mathrm{I}_{1}$, and $\mathrm{I}_{2}$ waves (dashed lines). The motoneuron response to this activity consisted of a series of small EPSPs (dashed line), with segmental delays ranging from 0.9 to $1.2 \mathrm{msec}$ after the relevant waves in the surface volley. There was no sign of any clear volley from F5 stimulation (two shocks) given alone, and no response was present in the motoneuron (gray lines). The conditioned responses (F5 + M1; continuous black lines) showed clear increases in both the $\mathrm{I}_{2}$ and $\mathrm{I}_{3}$ waves in the surface recording, and the late EPSPs associated with these components were also enhanced, in particular the EPSP occurring after the $\mathrm{I}_{3}$ wave. Neither the D-EPSP nor the $\mathrm{I}_{1}$-EPSP was changed.

An example of facilitation of an IPSP is shown in Figure $6 B$. In this case, test M1 stimulation (dashed lines) evoked small EPSPs in association with both the $\mathrm{D}$ and $\mathrm{I}_{2}$ waves. Both EPSPs were
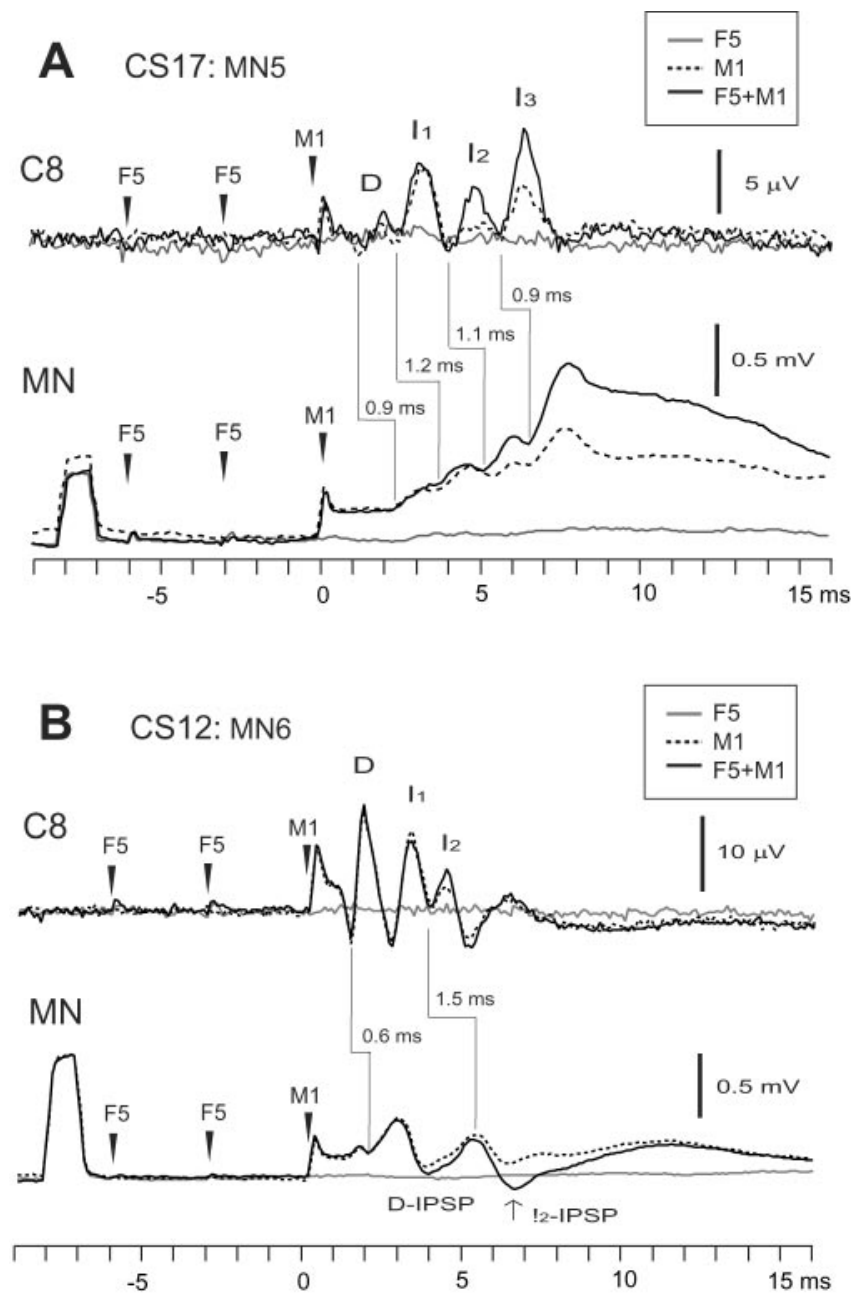

Figure 6. Facilitation of late EPSPs and IPSPs evoked from M1 by conditioning F5 stimulation. The top traces show surface recordings from $C 8$; the bottom traces show intracellular recording from identified motoneuron. $A$, Ulnar hand motoneuron. After a single $M 1$ shock ( - - ), each D and I wave in the surface volley was followed at monosynaptic latency by a small EPSP in the motoneuron: segmental latencies between positivity of surface volley and EPSP onset are indicated by vertical staggered lines. $\mathrm{F} 5$ alone produced no responses. Combined F5 $+\mathrm{M} 1$ stimulation (__ _ ) showed facilitation of $\mathrm{I}_{2}$ and $\mathrm{I}_{3}$ waves from $\mathrm{M} 1$ by conditioning $\mathrm{F} 5$ stimulation ( $C-T$ interval, 3 msec between second $F 5$ and M1 shocks). This also augmented the later EPSPs associated with the $\mathrm{I}_{2}$ and $\mathrm{I}_{3}$ waves. Stimuli:F5, $2 \times 120 \mu \mathrm{A} ; \mathrm{M1}, 1 \times 150 \mu \mathrm{A}$. The averages of 73 sweeps per condition are shown. $B$, Deep radial motoneuron. After M1 alone, small EPSPs after the $D$ and $I_{2}$ waves were followed by large IPSPS. The $I_{2}$-IPSP was facilitated by conditioning F5 stimulation Stimuli: F5, $2 \times 100 \mu \mathrm{A} ; \mathrm{M1}, 1 \times 200 \mu \mathrm{A}$. The averages of 113 sweeps per condition are shown.

immediately followed by a sharp IPSP; segmental latency to IPSP onset was $1.5 \mathrm{msec}$ in both cases. The later $\mathrm{I}_{2}$-IPSP was facilitated by conditioning F5 stimulation (continuous black line); none of the other features was affected.

Figure 7 shows responses from an ulnar motoneuron in CS13 to test stimulation of two different pairs of M1 electrodes, shown in the inset above. The effects from the first pair are shown in Figure 7A: a single shock to M1 electrodes 2 (cathode) and 1 (anode) evoked a D-EPSP and a second later EPSP after the $\mathrm{I}_{3}$ wave (dashed lines). F5 stimulation (two shocks) given alone evoked no visible descending volley or postsynaptic response (gray lines). However, when F5 stimulation preceded the M1 shock by 3 msec, there was a clear facilitation of the $\mathrm{I}_{3}$ wave and a marked increase in the amplitude of the late $\mathrm{I}_{3}$-EPSP (continuous black lines). When M1 electrodes 3 (cathode) and 4 (anode) were 

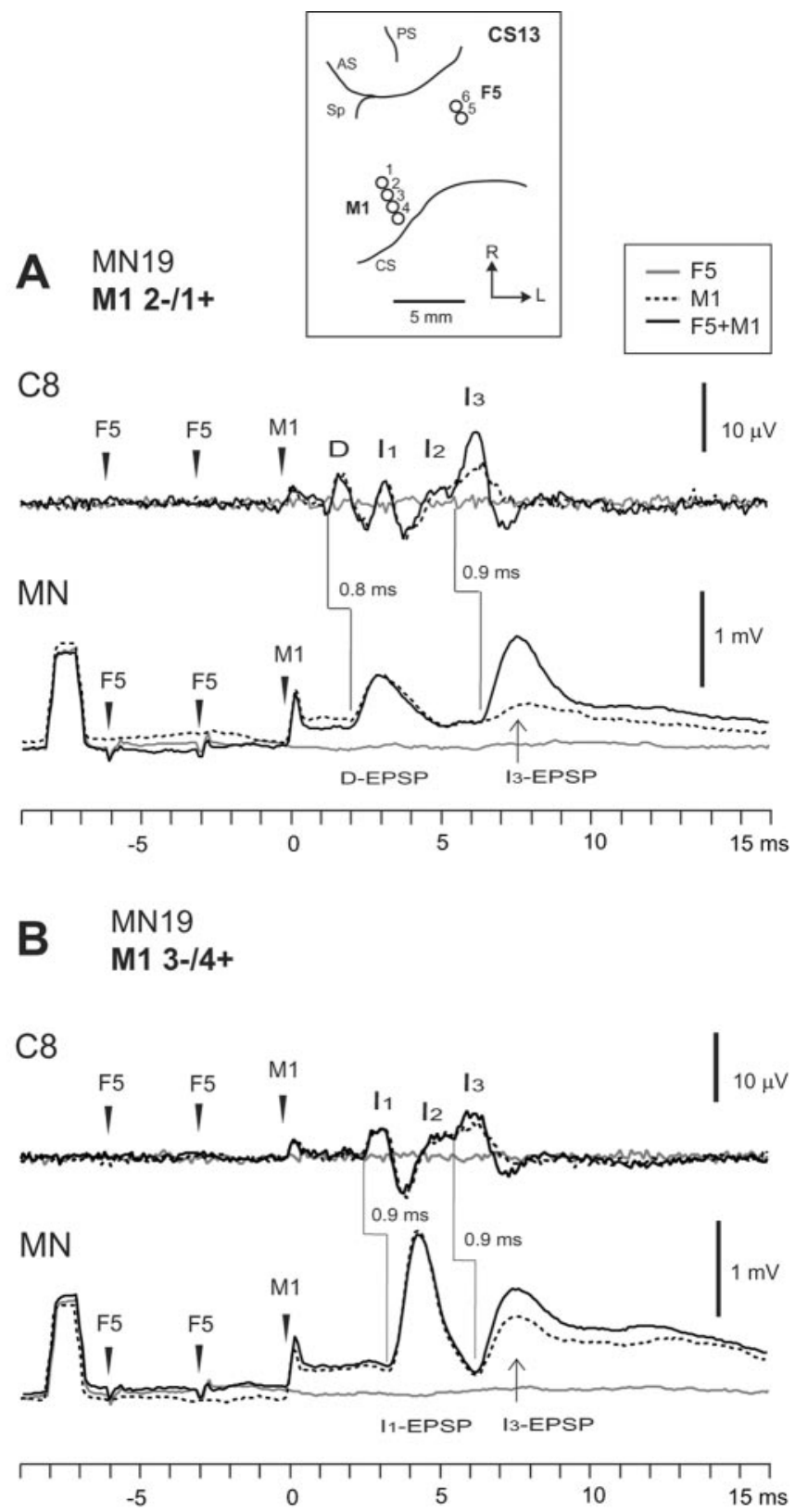

Figure 7. Facilitation of late EPSPs from F5 ulnar motoneuron, case CS13. A, Stimulation of M1 between electrodes 2 (cathode) and 1 (anode) evoked a D-EPSP ( 0.8 msec after the D wave) and an $I_{3}-E P S P\left(0.9\right.$ msec after the $I_{3}$ wave). The location of electrodes are shown in the inset. F5 stimulation alone (electrode 6 as cathode, electrode 5 as anode) produced no clear responses but, when combined with $M 1$ (C-T interval, $3 \mathrm{msec}$ ), gave a pronounced facilitation of the $I_{3}$ EPSP but did not affect the D-EPSP. Stimuli: F5, $2 \times 100 \mu \mathrm{A} ; \mathrm{M} 1,1 \times 200 \mu \mathrm{A}$. The averages of 100 sweeps per condition are shown. $B$, The same $F 5$ conditioning stimulus had a different effect on the responses evoked from a different $M 1$ test stimulus, now using electrode 3 as cathode and electrode 4 as anode. The test $\mathrm{M} 1$ shock gave $\mathrm{I}_{1}$ - and $\mathrm{I}_{3}$-EPSPs; only the latter was facilitated by conditioning $\mathrm{F} 5$ stimulation. Stimuli are the same as in $B$. The averages of 100 sweeps per condition are shown.

used (Fig. $7 B$ ), a very different pattern of descending activity and motoneuronal responses was observed: no D wave was present, and the motoneuron exhibited a large $\mathrm{I}_{1}$-EPSP, followed by an $\mathrm{I}_{3}$-EPSP (segmental latency, $0.9 \mathrm{msec}$ in both cases). Conditioning with $\mathrm{F} 5$ facilitated the later $\mathrm{I}_{3}$-EPSP, whereas the $\mathrm{I}_{1}$-EPSP was unchanged.

\section{Summary of motoneuron responses}

M1 stimulation

A total of 50 of 79 (63\%) motoneurons showed an early D-EPSP, whereas $42(53 \%)$ showed an $\mathrm{I}_{1}$-EPSP and $54(68 \%)$ responded with later EPSPs in association with $\mathrm{I}_{2}$ or $\mathrm{I}_{3}$ waves (Fig. $8 A$ ). IPSPs were observed in relation to the $\mathrm{D}$ wave $(22$ of $79 ; 28 \%)$, $\mathrm{I}_{1}$ wave (15 of 79; 19\%), or later waves (11 of 79; 15\%) (Fig. 8C).

\section{F5 stimulation}

Only late EPSPs, beginning at least $3 \mathrm{msec}$ after the F5 shock(s), were observed after F5 stimulation (Fig. 8D). These late EPSPs were observed in 44 of 79 (56\%) motoneurons; late IPSPs were seen in 16 of $79(20 \%)$ cases. In general, late EPSPs from F5 were always smaller than those from M1.

\section{Effects of interactions between F5 and M1 stimulation}

We did not observe any facilitation of the early EPSPs associated with either the $\mathrm{D}$ wave (Figs. $6 A, B, 7 B$ ) or the $\mathrm{I}_{1}$ wave (Figs. $6 A$, $7 C$ ). In contrast, facilitation of later EPSPs (Figs. $6 A, 7 B, C$ ) was observed in 47 of 79 motoneurons (60\%) (Fig. 8 A, black bar). In most cases, a late EPSP present after M1 stimulation given alone was facilitated; however, in nine motoneurons, a late EPSP appeared after conditioning stimulation that was not present in the test M1 condition. The facilitation of late EPSPs was particularly common among intrinsic hand motoneurons (12 of 13 or $92 \%$ ) (Fig. $8 \mathrm{~B}$, black bar), significantly higher than for forearm flexor or extensor motoneurons ( 35 of 66 or 53\%; $p<0.05, \chi^{2}$ test). In no case were EPSPs evoked from M1 suppressed by prior F5 stimulation.

We observed that the early IPSPs evoked from M1 and associated with the D and $\mathrm{I}_{1}$ waves were not affected by F5 stimulation, whereas later IPSPs were augmented in 10 of 79 motoneurons (Fig. $8 C$, black bar).

\section{Effects of muscimol microinjection in M1 hand area}

We reasoned that if $\mathrm{M} 1$ itself was the main site of facilitation from F5, then synaptic inactivation in the vicinity of the M1 array should abolish it. Accordingly, in three monkeys, small volumes of muscimol (1.6-6 $\mu \mathrm{l})$ were injected close to the M1 electrode array. The results shown in Figure 9 are from CS14, in which the smallest volume of muscimol was injected (see Materials and Methods). The later $\mathrm{I}_{2}$ and $\mathrm{I}_{3}$ waves evoked from M1 were completely abolished $40 \mathrm{~min}$ after muscimol injection, although there were only small decreases in the $\mathrm{I}_{1}$ wave and no change in $\mathrm{D}$ wave amplitude. Importantly, late I-waves from F5 were also substantially decreased (Fig. 9B). Finally, Figure $9 \mathrm{C}$ shows that the facilitation of the $\mathrm{I}_{2}$ and particularly the $\mathrm{I}_{3}$ waves by $\mathrm{F} 5$ conditioning stimulation was decreased $20 \mathrm{~min}$ after muscimol injection and completely abolished after $40 \mathrm{~min}$. Similar results were obtained in all three cases tested.

Figure $8, E$ and $F$, summarizes the results obtained from motoneuron recording before and after muscimol injection (CS14). Before muscimol (Fig. $8 E$ ), it was common to find motoneurons yielding late EPSPs, in association with the $\mathrm{I}_{2}$ and $\mathrm{I}_{3}$ waves, and these late EPSPs were facilitated from F5 (Fig. $8 E$, black bar). In the 3-4 hr after the injection, most motoneurons showed only early EPSPs (D- or $\mathrm{I}_{1}$-EPSPs) (Fig. $8 F$ ). None of these was facilitated by F5 conditioning. Only two motoneurons showed late EPSPs; neither of these was facilitated from F5.

\section{Investigation into the detailed time course of F5-evoked facilitation of M1 volleys}

Because the effects of interactions between F5 and M1 were to facilitate specific components of the descending corticospinal 


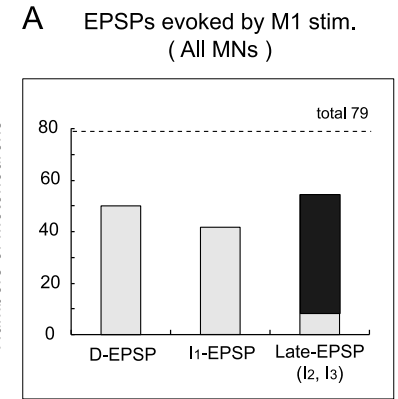

D EPSPs evoked by F5 stim. (All MNs)

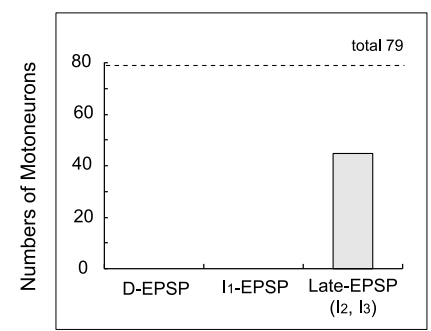

B EPSPs evoked by M1 stim. ( Intrinsic hand muscle MNs )

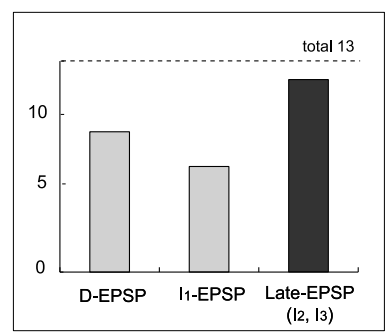

E EPSPs evoked by M1 stim. (Before Muscimol)

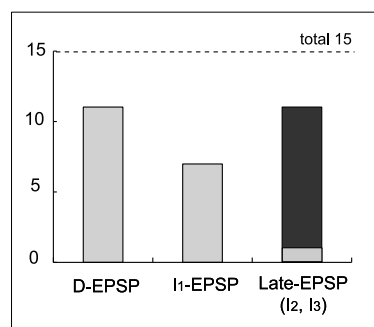

C IPSPs evoked by M1 stim. (All MNs)

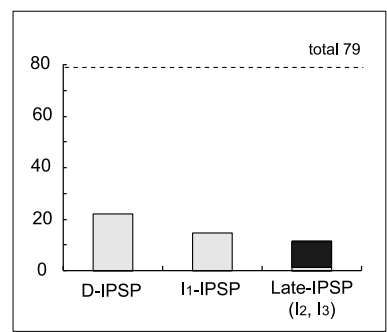

F $\quad$ EPSPs evoked by M1 stim. (After Muscimol)

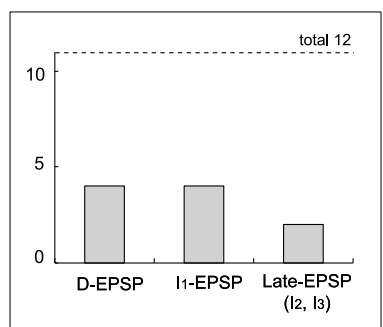

Figure 8. Summary of F5 facilitatory effects on motoneuronal EPSPs and IPSPs and effects of microinjection of muscimol in M1 on motoneuron responses. $A-D$, Bars chart the number of arm/hand motoneurons that showed postsynaptic responses to stimulation of M1 or F5. M1 stimulation evoked EPSPs $(A)$ associated with the D wave, $I_{1}$ wave, or the late $\left(I_{2}\right.$ and $\left.I_{3}\right)$ waves; EPSPs facilitated by conditioning F5 stimulation are indicated by the black bar: only late EPSPs from M1 were facilitated. This effect was particularly striking for the subset of motoneurons identified as supplying intrinsic hand muscles ( $B)$. C, M1-evoked IPSPs in a small proportion of motoneurons; again, only late IPSPs from M1 were facilitated by F5 stimulation (black bar). F5 stimulation alone gave rise to late, but not early, EPSPs (D). Data are from 79 motoneurons in five monkeys. The condition (F5)-test (M1) interval was either 3 or $3.6 \mathrm{msec}$. Test stimuli were single shocks to M1. For F5, either single (one monkey) or double (four monkeys) shocks were used. Stimulus intensity varied from 70 to $200 \mu \mathrm{A}$. E, F, Effects of microinjection of muscimol on EPSPs from M1 and their facilitation from F5. All data from case CS14. Motoneurons were recorded before ( $E$ ) and up to $4 \mathrm{hr}$ after muscimol microinjection in M1 ( $F$ ) (see Materials and Methods and the legend to Fig. 9). Before the injection, M1 stimulation yielded EPSPs in association with $\mathrm{D}, \mathrm{I}_{1}$, and $\mathrm{I}_{2} / \mathrm{I}_{3}$ waves; these late EPSPs were common, and only these EPSPs were facilitated by conditioning $\mathrm{F} 5$ stimulation ( $E$, black bar). After muscimol injection, late EPSPs from M1 were found in only two motoneurons; neither of these was facilitated from F5. M1: single shock, $100-200 \mu \mathrm{A} ; \mathrm{F5}$ : two shocks, $100-200 \mu \mathrm{A}$. C-T interval, $3.0 \mathrm{msec}$.

\section{A Stimulation M1: $400 \mu \mathrm{A}$}
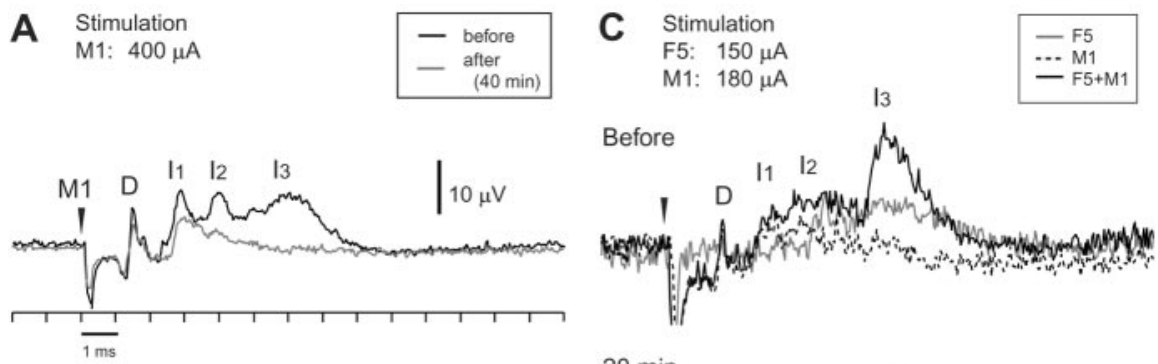

B Stimulation F5: $400 \mu \mathrm{A}$
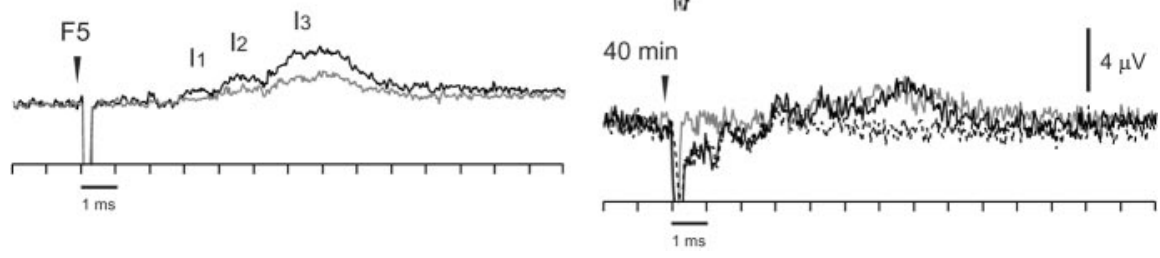

Figure 9. Effects of microinjection of muscimol into $\mathrm{M} 1$ on descending volleys from $\mathrm{M} 1$ and $\mathrm{F} 5$. All data are from case CS14. A, $M 1$ volleys: a single $400 \mu$ A shock to $M 1$ evoked D and I waves. After control recordings (before), a $0.5 \%$ solution of muscimol was injected close $(<2 \mathrm{~mm})$ to the microwire electrodes from which these effects were obtained; the total volume injected was $1.6 \mu \mathrm{l}$ in two tracks. Forty minutes later, the $I_{2}$ and $I_{3}$ waves were largely abolished; there was a small reduction in the $I_{1}$ wave and no obvious effect on the $D$ wave. The average of 150 sweeps is shown. $B$, A single $400 \mu$ A shock to $F 5$ evoked a small $I_{1}$ and larger $I_{3}$ wave; 40 min after the muscimol injection in M1, there was a marked reduction in both waves. The average of 150 sweeps is shown. C, Effects of muscimol on F5-M1 interaction. A single test M1 shock ( $180 \mu \mathrm{A})$ was conditioned by a single F5 shock (150 $\mu \mathrm{A})$, and the ( $-\mathrm{T}$ interval was $0 \mathrm{msec}$. Control recordings showed a marked facilitation of the $\mathrm{I}_{3}$ wave; 20 min after muscimol injection, this facilitation was considerably reduced, and it was abolished after $40 \mathrm{~min}$. The average of 100 sweeps is shown.

volleys from M1, we investigated the detailed time course of this facilitation to see whether peaks of interaction corresponded to the times at which I waves were generated in M1 (cf. Tokimura et al., 1996; Ziemann et al., 1998). This was investigated in two cases (CS14 and CS17), with recording from the rostral spinal cord electrode (C3). F5-M1 interaction was tested in 0.4 msec steps for C-T intervals ranging from $-3.6 \mathrm{msec}$ (M1 stimulus precedes F5) to $+6.0 \mathrm{msec}$ (F5 precedes M1). Single shocks were used. Additional intervals $(10,15,20$, and 30 $\mathrm{msec}$ ) were also tested. The duty cycle was $3 \mathrm{~Hz}$, and different C-T intervals were tested in a block design. Stimuli were given in a sequence of three: F5 alone, then M1 alone, and then F5 + M1. For each conditioned response sweep (F5 $+\mathrm{M} 1)$, we measured the peak voltage of a given component $\left(D, I_{1}, I_{2}\right.$, or $\left.I_{3}\right)$ and subtracted from it the algebraic sum of the same component evoked by M1 alone and by F5 alone. These values were derived from the sweeps given immediately before the F5 + M1 sweep; this approach minimized any effects attributable to slow changes in cortical excitability. This analysis was per- 
formed for each of 100 sets of stimuli at the interval being tested, and the mean amplitude of the "volley facilitation" ( \pm SE) was calculated. This is the amplitude of the component present in the conditioned response over and above the background value, and it is plotted against the C-T interval in Figure $10 \mathrm{~B}-E$. For statistical analysis, a paired $t$ test was performed for 100 pairs of test (M1 alone) versus conditioned [(F5 + M1) - F5 alone] responses at each $\mathrm{C}-\mathrm{T}$ interval investigated, with results being Bonferroni corrected for multiple comparisons. Finally, to compare effects on the different components, the amount of facilitation was normalized as a percentage of the component recorded in response to $\mathrm{M} 1$ alone (Fig. $10 \mathrm{~A}$ ).

The results confirmed marked facilitation of the later I waves: up to $300 \%$ for $\mathrm{I}_{3}$ and $175 \%$ for $\mathrm{I}_{2}$ (Fig. $10 \mathrm{~A}-\mathrm{C}$ ), with little or no effect on the $\mathrm{D}$ or $\mathrm{I}_{1}$ waves (Fig. $10 \mathrm{D}, \mathrm{E}$ ). Figure $10 \mathrm{~B}$ shows that a significant $(p<0.05)$ increase in the amplitude of $\mathrm{I}_{3}$ was first observed at the $-0.8 \mathrm{msec}$ interval. There followed a marked modulation in the degree of facilitation with the C-T interval, with peaks of facilitation occurring at $0,1.6,3.2,4.4$, and $5.6 \mathrm{msec}$ (Fig. 10 A, arrows). These intervals correspond closely to the well known I wave periodicity at around $1.2 \mathrm{msec}$ (Patton and Amassian, 1954; Kernell and Wu, 1967; Amassian et al., 1987; Edgley et al., 1997). The facilitation of the $\mathrm{I}_{3}$ wave declined slowly from 6 to $20 \mathrm{msec}$, returning to baseline by $30 \mathrm{msec}$.

Sustained facilitation of the $\mathrm{I}_{2}$ wave was not observed until $\sim 1.6 \mathrm{msec}$ (Fig. 10C), but this did not achieve significance ( $p<$ $0.05)$ until $3.2 \mathrm{msec}$, considerably later than the sustained increase in the $\mathrm{I}_{3}$ wave. Increased $\mathrm{I}_{2}$ activity lasted until $15 \mathrm{msec}$. The first peak in the $\mathrm{I}_{2}$ facilitation matched precisely that of the second $\mathrm{I}_{3}$ peak at $1.6 \mathrm{msec}$ (Fig. $10 \mathrm{~A}$, second arrow). There was also coincidence in later peaks (e.g., the second $\mathrm{I}_{2}$ peak with the third $\mathrm{I}_{3}$ peak at $3.2 \mathrm{msec}$ ) (Fig. $10 \mathrm{~A}$, third arrow).

We did not observe any facilitation of the $\mathrm{I}_{1}$ wave (Fig. $10 \mathrm{D}$ ), except at $10 \mathrm{msec}$, where it was small but significant. There was no significant facilitation of the D wave (Fig. 10E). No significant suppression of any component was seen.

\section{Discussion}

We have demonstrated that premotor cortex can facilitate corticospinal motor outputs from macaque M1 to arm and particularly hand motoneurons. The main facilitatory effects were observed on the later $\mathrm{I}_{2}$ and $\mathrm{I}_{3}$ indirect corticospinal volleys evoked from M1 and on responses of motoneurons to these volleys. The results suggest that F5 can facilitate neuronal circuits in M1 that generate these later volleys, and this would explain why F5-M1 facilitation was abolished by injection of muscimol in the hand area of M1.

\section{Corticospinal volleys evoked from M1 and F5}

Single bipolar stimuli of up to $200 \mu \mathrm{A}$ delivered to the M1 hand region evoked a characteristic pattern of a small $\mathrm{D}$ wave and a complex series of larger I waves (cf. Maier et al., 2002). In contrast, we saw no evidence for any D wave activation from F5. These findings are consistent with the relatively large corticospinal projection from M1 (around half of the total projection from the frontal lobe) (Dum and Strick, 1991) compared with the small projection from PMv (4\%). This small projection may have gone undetected in surface recordings, especially if the volley was slow and temporally dispersed. Corticospinal neurons in PMv do not project as far as lower cervical segments but terminate at more rostral levels (He et al., 1993; Galea and Darian-Smith, 1994). In keeping with these findings, we did not observe any short-latency EPSPs in motoneurons that could have been evoked by a D wave from F5.

Indirect or I waves were evoked from F5; they were small and had higher thresholds than from M1 (Fig. 3). The most prominent feature was the $\mathrm{I}_{3}$ wave. Two observations hint that at least part of the I wave activity evoked by stimulation in F5 actually arose from within M1. First, local injection of muscimol close to the M1 microwire array greatly reduced the amplitude of I waves evoked from F5 (Fig. 9B). The volume injected in CS14 (1.6 $\mu \mathrm{l}$ in two tracks) would not be expected to spread $>1-2 \mathrm{~mm}$ (Martin and Ghez, 1999), so it is unlikely to have been attributable to a direct GABAergic blockade of F5. Second, I waves evoked from F5 had fast conduction velocities $\left(\sim 80 \mathrm{~m} \cdot \mathrm{sec}^{-1}\right)$ and were identical to that of D and I waves evoked from M1. Corticospinal neurons in premotor cortex are smaller and more slowly conducting than in M1 (Murray and Coulter, 1981) (T. Brochier and R. N. Lemon, unpublished observations), making it unlikely that these fast I waves arose within F5 itself. Stimulation of premotor areas can evoke indirect responses from M1 corticospinal neurons (CSNs) (Amassian et al., 1987; Ghosh and Porter, 1988; Tokunu and Nambu, 2000).

\section{Facilitation of M1 outputs from F5}

Stimulation of F5 evoked a two- to fourfold increase in the later $\mathrm{I}_{2}$ and $\mathrm{I}_{3}$ corticospinal volleys evoked from the M1 hand area (Fig. $10 \mathrm{~A}$ ). This facilitation occurred at short C-T intervals and could be evoked by F5 conditioning shocks, which were themselves subthreshold for any corticospinal response (Fig. $4 E-H$ ). This facilitation showed evidence of periodicity, with peaks at 1.2-1.6 msec apart (Fig. 10A-C); it was completely abolished by local muscimol injection in M1 (Fig. 9C). The facilitation of late corticospinal volleys was reflected in robust increases in the later EPSPs associated with these volleys (Figs. 6-8); this was particularly striking for intrinsic hand muscle motoneurons (Fig. $8 \mathrm{~B}$ ).

\section{Site of interaction}

The facilitation by F5 of late EPSPs from M1 was often present without any detectable response in the motoneuron to F5 stimulation alone (Figs. 6A,7), indicating a premotoneuronal site of interaction. Because of the divergent projections from the two cortical areas stimulated, interaction could occur at a number of different cortical and subcortical sites (cf. Tanaka and Lisberger, 2002).

\section{Is M1 the site of interaction?}

The facilitation we observed in motoneurons was restricted to the late EPSPs that were time locked to the later $\mathrm{I}_{2}$ and $\mathrm{I}_{3}$ waves evoked from $\mathrm{M} 1$, and these EPSPs probably represent corticomotoneuronal action of corticospinal impulses in the $\mathrm{I}_{2}$ and $\mathrm{I}_{3}$ waves (Kernell and Wu 1967; Day et al., 1989; Edgley et al., 1997; Maier et al., 2002). Thus, the mechanisms in M1 generating the later I waves could have been facilitated from F5.

Three arguments support M1 as the interaction site. First, the earliest latency at which facilitation occurred was brief $[\mathrm{C}-\mathrm{T}=0$ msec (Fig. 5) and C-T $=-0.8 \mathrm{msec}$ (Fig. 10)]. Because conduction time from F5 to M1 is short ( $\sim 1.0 \mathrm{msec}$ ) (Godschalk et al., 1984), this would allow ample time for activity generated in F5 to facilitate interneuronal circuits generating the $I_{2}$ and $I_{3}$ waves. Second, injection of muscimol in M1 not only abolished the facilitation from $\mathrm{F} 5$ of the later $\mathrm{I}_{2}$ and $\mathrm{I}_{3}$ waves evoked from $\mathrm{M} 1$ but also abolished late EPSPs in motoneurons and their facilitation from F5 (Figs. 8, 9). Finally, the detailed time course of the F5-M1 interaction showed a series of peaks with a periodicity of $\sim 1.2-$ 

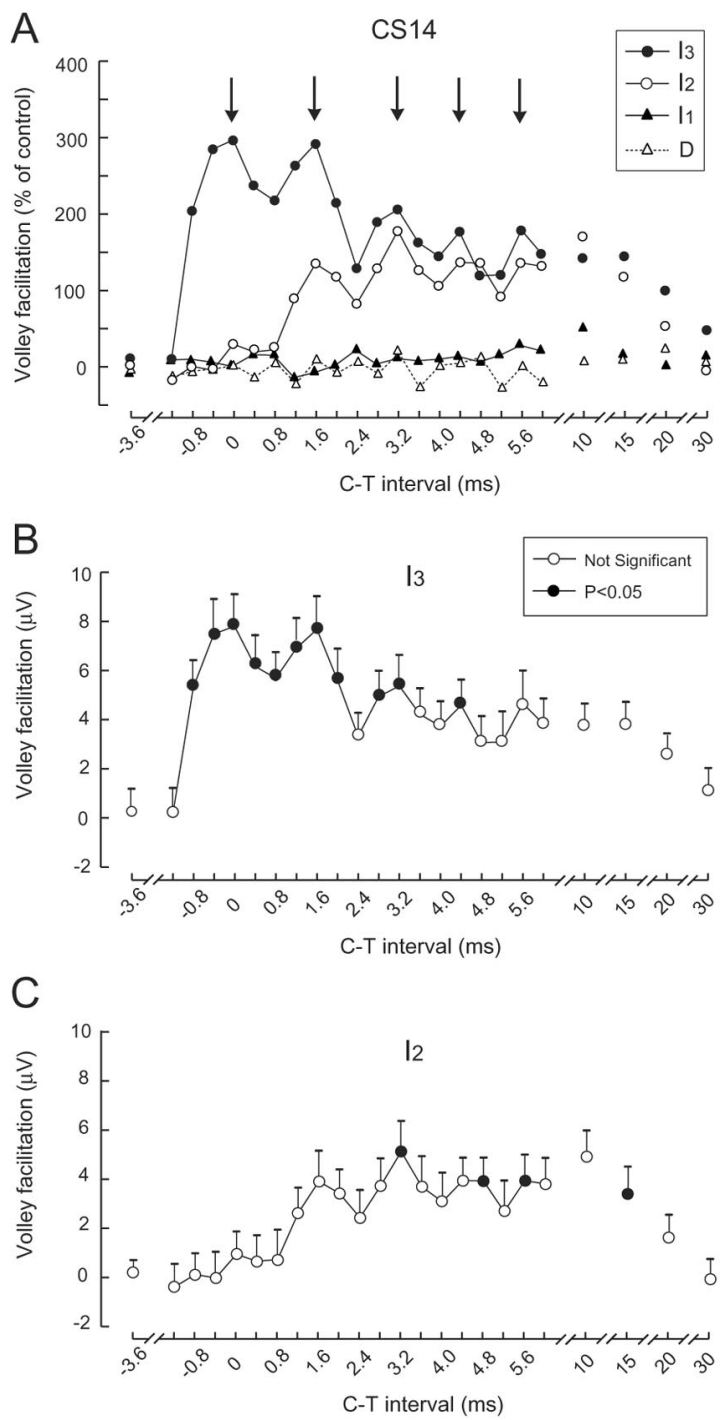

D

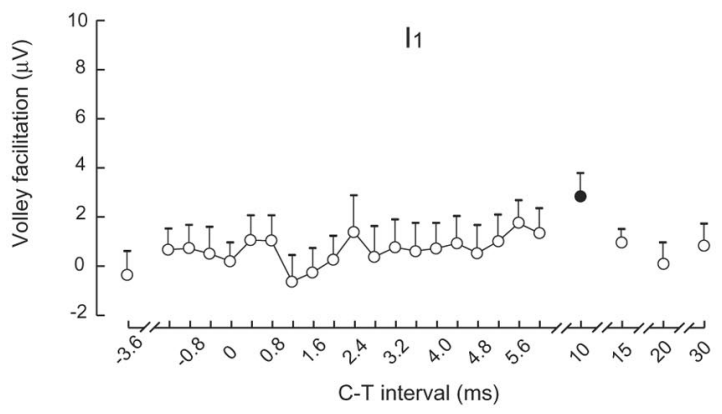

E

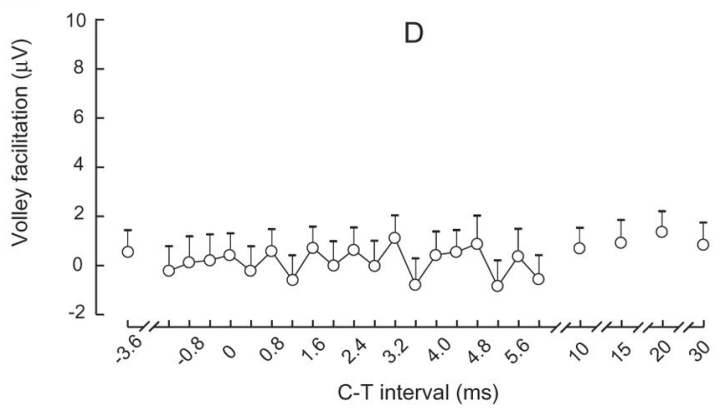

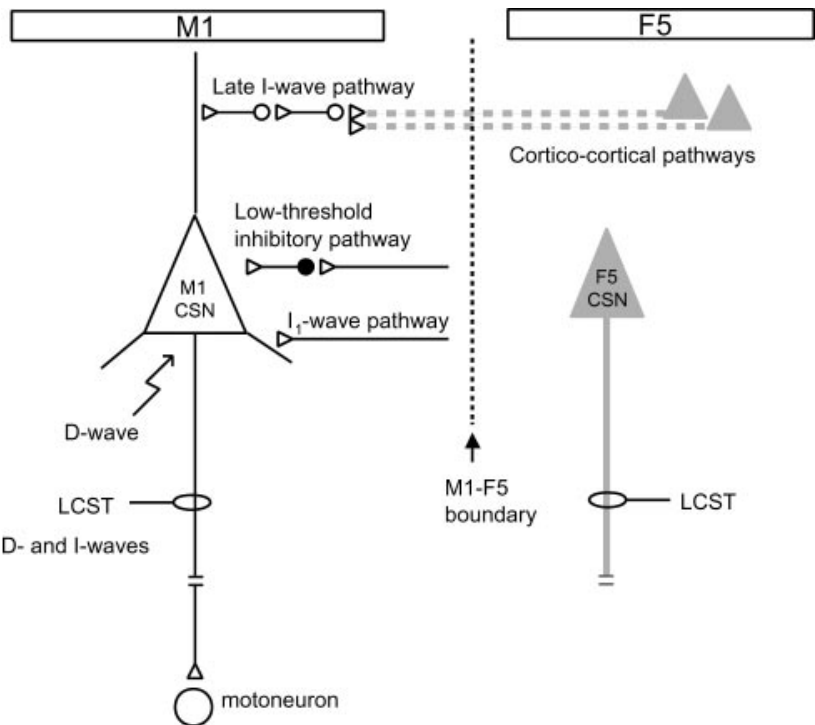

Figure 11. Possible mechanism explaining facilitation of late I waves Elements in black, on the left of the diagram, represent the three classes of excitatory inputs to CSNs: the D wave, the $\mathrm{I}_{1}$ wave, and the later $\left(\mathrm{I}_{2}\right.$ and $\left.\mathrm{I}_{3}\right)$ waves. A low-threshold inhibitory input pathway is al so shown. These four inputs are all excited by stimulation within M1. A similar set of inputs would be excited to CSNs in the premotor cortex (F5), but these are omitted for the sake of clarity. The model proposes that the main excitatory input from $\mathrm{F} 5$ to $\mathrm{M} 1$ converges on the interneuronal mechanisms in $\mathrm{M} 1$ giving rise to the $\mathrm{I}_{2}$ and $\mathrm{I}_{3}$ waves, thereby allowing $\mathrm{F} 5$ to influence I wave generation in M1 CSNs. Note that although M1 CSNs project directly to hand motoneurons, this is not the case for those located in F5. For detailes, see Discussion and llic et al. (2002).

$1.6 \mathrm{msec}$ (Fig. 10), and this is to be expected if facilitation acts on the cortical circuits generating the $\mathrm{I}_{2}$ and $\mathrm{I}_{3}$ waves. If most of the descending corticospinal activity evoked from $\mathrm{M} 1$ actually arose within $\mathrm{M} 1$, then the waxing and waning of the facilitatory drive from F5 would be best explained by an interaction within M1 itself.

\section{Proposed cortical mechanism}

The model in Figure 11 is based on that of Ilic et al. (2002), who studied the interaction of pairs of transcranial magnetic stimulation (TMS) pulses delivered to the human motor cortex. Four separate inputs to an M1 CSN are shown: D responses are attributable to direct activation at the axon hillock or main axon (Amassian et al., 1987). Indirect waves arise either through stimulation of presynaptic inputs to the CSN, producing the $\mathrm{I}_{1}$ response, or through a late I wave interneuronal pathway giving rise to the $\mathrm{I}_{2}$ and $\mathrm{I}_{3}$ components (Ziemann and Rothwell, 2000). This latter pathway is more complex and less secure than the $\mathrm{I}_{1}$ synaptic pathway (di Lazzaro et al., 1999). Finally, inhibitory inputs

\section{$\leftarrow$}

Figure 10. Detailed time course of effect of $\mathrm{F} 5-\mathrm{M} 1$ interaction on corticospinal volleys. The effect of interacting a single F5 stimulus $(200 \mu \mathrm{A})$ with a single M1 shock $(180 \mu \mathrm{A})$ was tested at a wide range of condition (F5) and test (M1) intervals, performed in a pseudorandom order from $-3.6 \mathrm{msec}$ (M1 before F5) to $6.0 \mathrm{msec}$ in $0.4 \mathrm{msec}$ steps and then at longer intervals out to $30 \mathrm{msec}$. The facilitation of a given component of the recorded descending activity ( $D$ wave and different I wave) was determined by subtracting from the conditioned response [(F5 $+M 1)$, the algebraic sum of the response to test and condition stimuli, given alone (i.e., (F5 + M1) $((\mathrm{F} 5)+(\mathrm{M} 1))]$. In $B-E$, the absolute value of this "volley facilitation" ( $\pm \mathrm{SE})$ has been plotted for the $I_{3}, I_{2}, I_{1}$, and $D$ waves, respectively. A significant difference between conditioned and test values was estimated with paired $t$ tests: Bonferroni-corrected significant differences $(p<$ 0.05 ) are indicated by filled circles; open circles indicate not significant differences. In $A$, the amplitude changes of the different components have been plotted on the same scale, normalized to the percentage of the test alone response. 
mediate the intracortical inhibition that can be observed after TMS or ICMS (Baker et al., 1998; Ziemann and Rothwell, 2000; Ilic et al., 2002).

We suggest that the corticocortical pathways excited by F5 stimulation terminate preferentially on the cortical interneurons involved in generation of the late I waves, explaining why the D and $I_{1}$ waves were not facilitated to the same extent as the later I waves. The late I wave pathway is probably oligosynaptic, with conduction delays in the order of $2-4 \mathrm{msec}$. It is more susceptible to $\mathrm{GABA}_{\mathrm{A}}$ agonists such as diazepam and muscimol than the $\mathrm{I}_{1}$ pathway, which does not involve separate interneuronal elements (Ilic et al., 2002); this would explain why muscimol depressed the $\mathrm{I}_{2}$ and $\mathrm{I}_{3}$ components and abolished their facilitation from F5 (Fig. 9).

\section{Possible functional significance of F5-M1 facilitation Effects of F5-M1 interaction on hand muscle EMG}

The results obtained clarify the facilitation from F5 of M1-evoked responses in intrinsic hand muscle EMG (Cerri et al., 2003). These effects were observed in two of the monkeys (CS13 and CS14) used in this study. Stimuli delivered through the same microwire electrodes in F5 and M1 that had previously facilitated EMG, produced facilitation of corticospinal volleys and EPSPs in the terminal experiment. The time course of the facilitation of volleys (Fig. 10) and of EMG [Cerri et al. (2003), their Fig. 7] were very similar, with robust effects from $\mathrm{F} 5$ observed at short $\mathrm{C}-\mathrm{T}$ intervals $(\sim 1 \mathrm{msec})$. The latency of the EMG responses to M1 stimulation was consistent with motoneurons discharging in response to $\mathrm{I}_{2}$ or $\mathrm{I}_{3}$ corticospinal input. Coincidence of F5 facilitatory effects on $\mathrm{I}_{2}$ and $\mathrm{I}_{3}$ waves, as shown by the arrows in Figure $10 \mathrm{~A}$, would lead to temporal facilitation of corticospinal inputs to motoneurons and explain the large increases in EMG response (and reductions in latency) that were produced by F5 conditioning. There were also signs of periodicity in the time course of EMG facilitation, which may reflect the I wave results shown in Figure 10.

\section{Relevance to TMS studies in humans}

In contrast to the excitatory actions documented here, most reports on premotor-motor cortex interactions with TMS in humans have stressed inhibitory effects (Civardi et al., 2001; Münchau et al., 2002). We selected only F5 sites giving rise to excitation, and these excitatory effects were focal in nature (Fig. 7) (Cerri et al., 2003). The inhibitory effects evoked by TMS may reflect a rather less focused inhibitory convergence on M1 from different premotor areas. We have not yet seen evidence for an inhibitory effect of F5 stimulation, and Cerri et al. (2003) did not see any evidence of ongoing EMG activity being suppressed by F5 stimulation. Although specific facilitation from F5 would excite appropriate outputs from M1, it could have widespread inhibitory effects on other outputs.

\section{Transmission of activity related to control of grasping}

We suggest that the pathways excited by single intracortical stimuli might also be involved in the transmission of information from F5 to M1 during visually guided grasp. Neurons in the same bank region of the inferior arcuate sulcus are specifically active during grasping movements (Murata et al., 1997), and these movements are degraded by reversible inactivation of this region (Fogassi et al., 2001). The facilitation of late EPSPs was particularly striking in hand motoneurons (Fig. $8 \mathrm{~B}$ ). The next step might be to determine whether, in the awake monkey, F5 facilitation of M1-driven activity in hand muscles is specifically facilitated during performance of a visuomotor grasping task.
Finally, there are interesting parallels between the results described here and those reported for gain control of smooth pursuit eye movements (Tanaka and Lisberger, 2001, 2002). These authors found that trains of stimuli delivered to the "frontal pursuit area," which is located in the frontal eye fields rostral to the arcuate sulcus, could modulate several features of pursuit eye movements made by awake monkeys, including a gain control of ongoing movements. The facilitation exerted by F5 on motor outputs from M1 may also act as a gain control system on these outputs; this could be part of a wider control system that helps to shape the pattern of activity across different hand muscles appropriate for grasp of specific objects.

\section{References}

Amassian VE, Stewart M, Quirk GJ, Rosenthal JL (1987) Physiological basis of motor effects of a transient stimulus to cerebral cortex. Neurosurgery 20:74-93.

Baker SN, Olivier E, Lemon RN (1998) An investigation of the intrinsic circuitry of the motor cortex of the monkey using intra-cortical microstimulation. Exp Brain Res 123:397-411.

Cerri G, Shimazu H, Maier MA, Lemon RN (2003) Facilitation from ventral premotor cortex of primary motor cortex outputs to macaque hand muscles. J Neurophysiol 90:832-842.

Civardi C, Cantello R, Asselman P, Rothwell JC (2001) Transcranial magnetic stimulation can be used to test connections to primary motor areas from frontal and medial cortex in humans. NeuroImage 14:1444-1453.

Day BL, Dressler D, Maertens de Noordhout A, Marsden CD, Nakashima K, Rothwell JC, Thompson PD (1989) Electric and magnetic stimulation of human motor cortex: surface EMG and single motor unit responses. J Physiol (Lond) 412:449-473.

di Lazzaro V, Oliviero A, Profice P, Insola A, Mazzone P, Tonali P, Rothwell JC (1999) Effects of voluntary contraction on descending volleys evoked by transcranial electrical stimulation over the motor cortex hand area in conscious humans. Exp Brain Res 124:525-528.

Dum RP, Strick PL (1991) The origin of corticospinal projections from the premotor areas in the frontal lobe. J Neurosci 11:667-689.

Dum RP, Strick PL (2002) Motor areas in the frontal lobe of the primate. Physiol Behav 77:677-682.

Edgley SA, Eyre JA, Lemon RN, Miller S (1997) Comparison of activation of corticospinal neurones and spinal motoneurones by magnetic and electrical stimulation in the monkey. Brain 129:839-853.

Fogassi L, Gallese V, Buccino G, Craighero L, Fadiga L, Rizzolatti G (2001) Cortical mechanism for the visual guidance of hand grasping movements in the monkey. A reversible inactivation study. Brain 124:571-586.

Galea MP, Darian-Smith I (1994) Multiple corticospinal neuron populations in the macaque monkey are specified by their unique cortical orgins, spinal terminations, and connections. Cereb Cortex 4:166-194.

Ghosh S, Porter R (1988) Corticocortical synaptic influences on morphologically identified pyramidal neurones in the motor cortex of the monkey. J Physiol (Lond) 400:617-629.

Ghosh S, Brinkman C, Porter R (1987) A quantitative study of the distribution of neurons projecting to the precentral motor cortex in the monkey (M. fascicularis). J Comp Neurol 259:424-444.

Godschalk M, Lemon RN, Kuypers HGJM, Ronday HK (1984) Cortical afferents and efferents of monkey post-arcuate area: an anatomical and electrophysiological study. Exp Brain Res 56:410-424.

Godschalk M, Mitz AR, Van Duin B, Van der Burg H (1995) Somatotopy of monkey premotor cortex examined with microstimulation. Neurosci Res 23:269-279.

He S-Q, Dum RP, Strick PL (1993) Topographic organization of corticospinal projections from the frontal lobe: motor areas on the lateral surface of the hemisphere. J Neurosci 13:952-980.

Hepp-Reymond M-C, Husler EJ, Maier MA, Qi H-X (1994) Force-related neuronal activity in two regions of the primate ventral premotor cortex. Can J Physiol Pharmacol 72:571-579.

Ilic TV, Meintzschel F, Cleff U, Ruge D, Kessler KR, Ziemann U (2002) Short-interval paired-pulse inhibition and facilitation of human motor cortex: the dimension of stimulus intensity. J Physiol (Lond) 545:153-167.

Jeannerod M, Arbib MA, Rizzolatti G, Sakata H (1995) Grasping objects: 
the cortical mechanisms of visuomotor transformation. Trends Neurosci 18:314-320.

Kakei S, Hoffman DS, Strick PL (1999) Muscle and movement representations in the primary motor cortex. Science 285:2136-2139.

Kakei S, Hoffman DS, Strick PL (2001) Direction of action is represented in the ventral premotor cortex. Nat Neurosci 4:1020-1025.

Kakei S, Hoffman DS, Strick PL (2003) Sensorimotor transformations in cortical motor areas. Neurosci Res 46:1-10.

Kernell D, Wu C-P (1967) Responses of the pyramidal tract to stimulation of the baboon's motor cortex. J Physiol (Lond) 191:653-672.

Lemon RN (1984) Methods for neuronal recording in conscious animals. In: IBRO handbook series: methods in neurosciences (Smith AD, ed), pp 162. London: Wiley.

Lemon RN, Kirkwood PA, Maier MA, Nakajima K, Nathan P (2004) Direct and indirect pathways for corticospinal control of upper limb motoneurones in the primate. In: Brain mechanisms for the integration of posture and movement. Progress in Brain Research, Vol 143 (Mori S, Stuart DG, Wiesendanger M, eds), pp 263-279. Amsterdam: Elsevier.

Maier MA, Illert M, Kirkwood PA, Nielsen J, Lemon RN (1998) Does a C3-C4 propriospinal system transmit corticospinal excitation in the primate? An investigation in the macaque monkey. J Physiol (Lond) 511:191-212.

Maier MA, Armand J, Kirkwood PA, Yang H-W, Davis JN, Lemon RN (2002) Differences in the corticospinal projection from primary motor cortex and supplementary motor area to macaque upper limb motoneurons: an anatomical and electrophysiological study. Cereb Cortex 12:281-296.

Martin JH, Ghez C (1999) Pharmacological inactivation in the analysis of the central control of movement. J Neurosci Methods 86:145-159.

Matelli M, Camarda R, Glickstein M, Rizzolatti G (1986) Afferent and efferent projections of the inferior area 6 in the macaque monkey. J Comp Neurol 251:281-298.

Muakkassa K, Strick P (1979) Frontal lobe inputs to primate motor cortex: evidence for somatotopically organized premotor areas. Brain Res 177:176-182.

Munchau A, Bloem BR, Irlbacher K, Trimble MR, Rothwell JC (2002) Functional connectivity of human premotor and motor cortex explored with repetitive transcranial magnetic stimulation. J Neurosci 22:554-561.
Murata A, Fadiga L, Fogassi L, Gallese V, Raos V, Rizzolatti G (1997) Object representation in the ventral premotor cortex (area F5) of the monkey. J Neurophysiol 78:2226-2230.

Murray EA, Coulter JD (1981) Organization of corticospinal neurons in the monkey. J Comp Neurol 195:339-365.

Patton HD, Amassian VE (1954) Single- and multiple-unit analysis of cortical stage of pyramidal tract activation. J Neurophysiol 17:345-363.

Porter R, Lemon RN (1993) Corticospinal function and voluntary movement. Physiological Society monograph. Oxford: Oxford UP.

Ranck JB (1975) Which elements are excited in electrical stimulation of mammalian central nervous system: a review. Brain Res 98:417-440.

Rizzolatti G, Luppino G, Matelli M (1998) The organization of the cortical motor system: new concepts. Electroencephalogr Clin Neurophysiol 106:283-296.

Rizzolatti G, Fogassi L, Gallese V (2002) Motor and cognitive functions of the ventral premotor cortex. Curr Opin Neurobiol 12:149-154.

Suzuki H, Azuma M (1976) A glass-insulated "elgiloy" microelectrode for recording unit activity in chronic monkey experiments. Electroencephalogr Clin Neurophysiol 41:93-95.

Tanaka M, Lisberger SG (2001) Regulation of the gain of visually guided smooth-pursuit eye movements by frontal cortex. Nature 409:191-194.

Tanaka M, Lisberger SG (2002) Enhancement of multiple components of pursuit eye movements by microstimulation in the arcuate frontal pursuit area in monkeys. J Neurophysiol 87:802-818.

Tokimura H, Ridding MC, Tokimura Y, Amassian VE, Rothwell JC (1996) Short latency facilitation between pairs of threshold magnetic stimuli applied to human motor cortex. Electroencephalogr Clin Neurophysiol 101:263-272.

Tokuno H, Nambu A (2000) Organization of nonprimary motor cortical inputs on pyramidal and nonpyramidal tract neurons of primary motor cortex: an electrophysiological study in the macaque monkey. Cereb Cortex 10:58-68.

Ziemann U, Rothwell JC (2000) I-waves in motor cortex. J Clin Neurophysiol 17:397-405.

Ziemann U, Tergau T, Wassermann EM, Wischer S, Hildebrandt J, Paulus W (1998) Demonstration of facilitatory I wave interaction in the human motor cortex by paired transcranial magnetic stimulation. J Physiol (Lond) 511:181-190 